\title{
Contraceptive counselling in abortion care
}

\author{
Helena Kilander
}

1.U UNKÖDNG

Department of Medical and Health Sciences

Linköping University, Sweden

Linköping 2018 
(c)Helena Kilander, 2018

Printed in Sweden by LiU-Tryck, Linköping, Sweden, 2018

ISBN 978-91-7685-264-4

ISSN 0345-0082 
To all women who have shared their stories with me!

"I dream of the day when every new born child is welcome." Elise Ottesen-Jensen 



\section{CONTENTS}

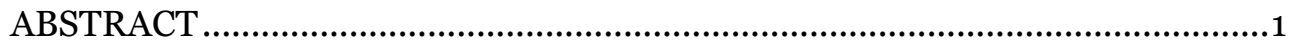

LIST OF PAPERS .............................................................................. 5

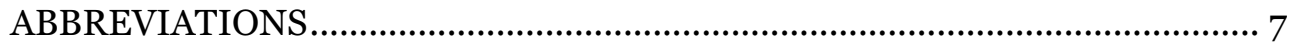

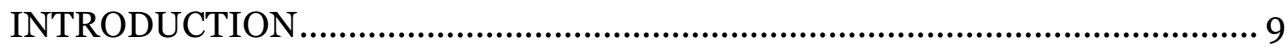

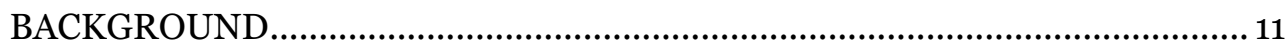

Sexual and reproductive health ............................................................... 11

Contraceptive counselling at the time of ...............................................14

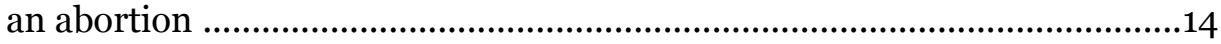

Prevalence of contraceptive use ....................................................... 17

Contraceptive and abortion care in Sweden ..........................................19

To improve contraceptive counselling and services in abortion care .............20

Theoretical framework ....................................................................... 22

Prevention and health promotion .......................................................... 22

Person-centred care ..................................................................................... 23

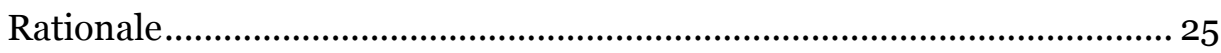

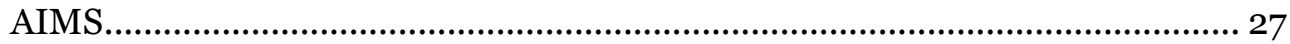

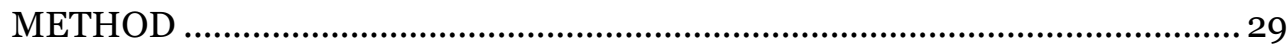

Designs and settings..................................................................... 29

Samples and characteristics of participants ..................................... 31

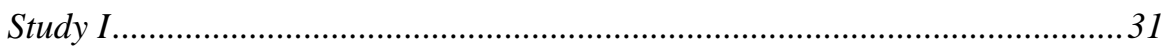

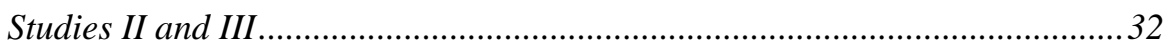

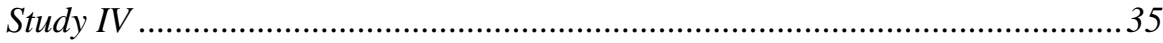

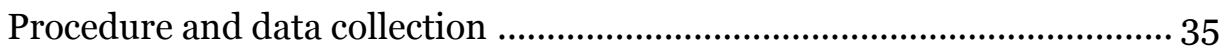

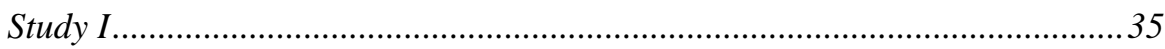

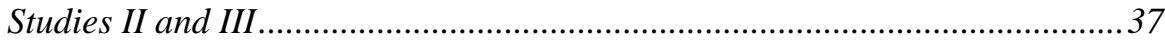

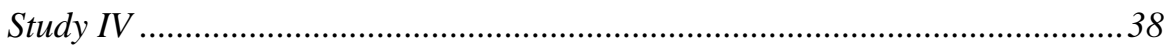

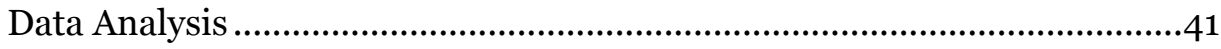

Quantitative Data Analysis ........................................................................ 41

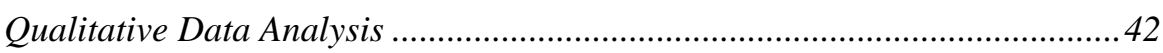


Ethical considerations .............................................................................. 46

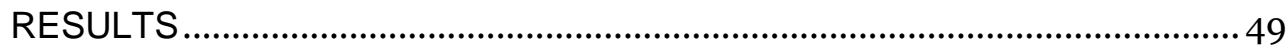

Contraceptive counselling - a complex meeting at the time of an abortion

Women's choices, need for guidance and access to contraceptive methods

To collaboratively design and seek to improve counselling and services in abortion care............................................................................. 57

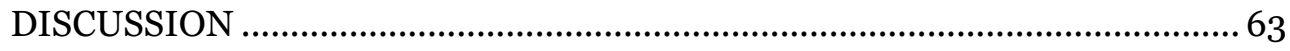

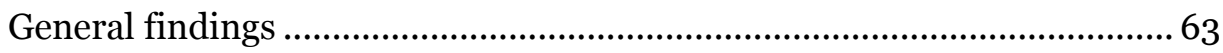

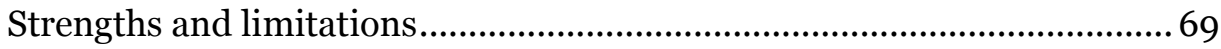

Validity and reliability ................................................................................... 72

Clinical implications................................................................................. 75

Future research ....................................................................................... 76

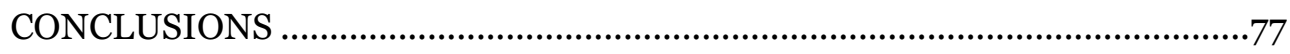

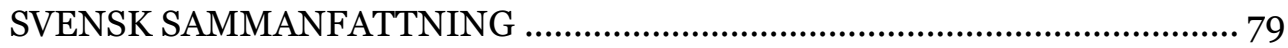

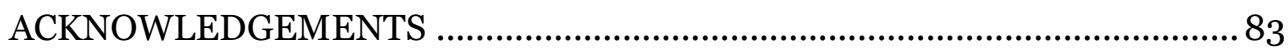

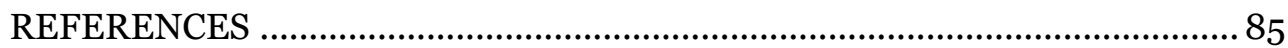




\section{ABSTRACT}

Introduction Improving women's knowledge about contraception, and their access to contraceptive methods, is central in order to strengthen their sexual and reproductive rights at the time of an abortion. Contraceptive counselling aims to support women's reproductive control and prevent unintended pregnancies (UPs). It is unclear, however, how to provide contraceptive counselling and how to organise services at the time of an abortion, in order to achieve this.

Aim The overall aim was to study women's choices and use of contraceptive methods post-abortion. The research also aimed to describe contraceptive counselling in the context of an abortion from women's and health professionals' (HP's) perspectives. Initial studies informed subsequent improvement efforts, also evaluated in the thesis, regarding contraceptive counselling and services at the time of an abortion.

Design and Methods The studies in this thesis involve both quantitative (studies I and IV) and qualitative (studies II-IV) methods, performed at six departments in southeast Sweden. Study I had a quantitative and longitudinal design. The medical records of women $(n=987)$ were reviewed regarding women's choice of contraceptive method at the index abortion and the odds of repeat abortion within three to four years. Studies II and III were qualitative interview studies, in which 13 women (study II) and 21 healthcare professionals (HPs) (study III) described their experiences of contraceptive counselling at the time of an abortion. The interviews were analysed using interpretive phenomenology (study II) and conventional content analysis (study III). Study IV was a case study regarding a qualitative improvement collaborative (QIC), designed to improve contraceptive counselling and 
services. Three multi-professional teams involved in abortion care participated in the QIC and two women provided user-experience input. Both qualitative and quantitative data were collected and analysed.

Results The findings of the thesis are organised into three themes:

I) Women and HPs described contraceptive counselling at the time of an abortion as an often - complex meeting. There was scepticism about contraceptive methods and limited receptivity to information among women. Respectful counselling facilitated women's choice of contraceptive method even if they were sceptical and found the situation emotionally charged. II) Women's choices, need for guidance and access to the contraceptive methods was described in the second theme. Choice of oral contraceptives (OC) dominated. Overall, 25\% of the women experienced repeat abortion during follow-up. Women who chose longacting reversible contraception (LARC) experienced fewer repeat abortions compared to women who chose OC. Both women and HPs reported barriers in access to LARC post-abortion. III) In a Quality Improvement Collaborative (QIC), two volunteering women provided user-experience input. HPs participating in this QIC reported strengthened skills in counselling and enhanced ability to evaluate their performance. Despite the team's prediction that they would reach the QIC goal that $\geq 50 \%$ of women would start LARC within 30 days post-abortion, and the fact that a majority of the women in QIC units chose LARC, none of the teams managed to reach the goal, primarily due to insufficient capacity for timely initiation of LARC.

Conclusion The findings suggest that women need respectful counselling and guidance at the time of an abortion. Access to a range of contraceptive methods, particularly LARC, is important to prevent repeat UPs. There is room for further improvement in offering coordinated and 
timely access for women who choose LARC, and to evaluate counselling, in the present settings.

Keywords; Accessibility, Oral contraceptives, Collaboratives, Long Acting Reversible Contraception, Prevention, Repeat abortion, Respect, Reproductive control, Unintended pregnancy. 


\section{LIST OF PAPERS}

I. Kilander H, Alehagen S, Svedlund L, Westlund K, Thor J \& Brynhildsen J, (2016). Likelihood of repeat abortion in a Swedish cohort according to the choice of post-abortion contraception: A longitudinal study. Acta et Obstetrica and Gynecologica Scandinavia. 95(5).565-571.

Doi: 10.1111/aogs.12874

II. Kilander H, Berterö C, Thor J, Brynhildsen J \& Alehagen S, (2018). Women's experiences of contraceptive counselling in the context of an abortion: An interview study.

Sexual \& Reproductive Healthcare. 17.103-107.

Doi:10.1016/j.srhc.2018.07.007

III. Kilander H, Salomonsson B, Thor J, Brynhildsen J \& Alehagen S, (2016). Contraceptive counselling of women seeking abortion: A qualitative interview study of health professionals' experiences. The European Journal of Contraception \& Reproductive health care. 22(1).1-8.

Doi:10.1080/13625187.2016.1238892

IV. Kilander H, Brynhildsen J, Alehagen S, Fagercrantz A \& Thor J, (2018). Collaboratively seeking to improve contraceptive counselling at the time of an abortion: A case study in Sweden. Submitted.

The published articles have been reprinted with the permission of the copyright holders. 


\section{ABBREVIATIONS}

COC Combined oral contraceptive

$\mathrm{Cu}$-IUDs Copper intrauterine devices

HPs Health professionals

LARC Long-acting reversible contraception

LNG- IUS Levonorgestrel-intrauterine systems

LS Learning session

MI Motivational interviewing

OC Oral contraceptives

PCC Person-centred care

RPL Reproductive life planning

SDM Shared decision-making

SRH Sexual and reproductive health

SRHR Sexual, reproductive health and rights

QIC Quality improvement collaborative

UPs Unintended pregnancies 


\section{INTRODUCTION}

Globally every year, 44 million women of all ages are estimated to have an induced abortion [1]. The time of an abortion is thought of as a key opportunity to fulfil women's needs of effective contraception to prevent repeat unintended pregnancies (UPs) [2-4]. All women have the right to receive knowledge and guidance regarding how to avoid an UP at the time of an abortion [5, 6]. However, a considerable number of women experience repeat UPs and abortions despite contraceptive use [3, 7, 8]. These women face greater socioeconomic challenges than others. This indicates a need to improve contraceptive counselling and services at the time of an abortion [9-13].

Contraceptive counselling following an abortion seems to differ from contraceptive counselling in general, as the abortion often involves complex decisions [14-16]. There is still limited knowledge regarding how to design contraceptive counselling in the context of an abortion, in order to help women to avoid repeat UPs [17-19].

This thesis seeks to provide an understanding of different aspects of contraceptive methods and contraceptive counselling at the time of an abortion. It also aims to gain insights into women's and health professionals' (HP's) experiences of the issue as well as collaborative efforts aimed at designing and seeking to improve contraceptive counselling. I hope that the results of this thesis will encourage continued work to improve contraceptive counselling and services for women experiencing an abortion. 


\section{BACKGROUND}

\section{Sexual and reproductive health}

Sexual and reproductive health (SRH) is nowadays intertwined in one broad framework by the World Health Organisation and defined as the fulfilment of emotional, physical and social wellbeing in sexuality. The definition of sexual, reproductive health and rights (SRHR) includes reproductive rights, such as having a satisfying, safe sexual life, as well as freedom to decide when to reproduce and with whom. Furthermore, SRHR involve the rights of individuals to receive knowledge regarding how to effectively prevent unintended pregnancy (UP) and sexual infections [5].

In contrast to reproductive rights, there is no internationally accepted definition of sexual rights. However, sexual rights are included in human rights and include the right of all people to decide on their own body and sexuality $[6,20,21]$. There is a value to establishing SRHR as a combined term in developing programmes, as all of these parts are central, and none subordinates the others. A rights and norm-critical perspective is essential and necessary in pursuing work on SRHR [5, 6, 20-22].

Improving people's wellbeing in sexuality is closely connected to cultural and social norms, gender, socioeconomic inequalities, and human rights, as well as laws and policies [5]. A considerable number of women still have limited sexual and reproductive rights. They report unmet needs for contraceptives [23-27] and experience limited access to safe abortions [28]. Approximately 25.1 million unsafe abortions occurred each year between 2010 and 2014. Many countries lack statistics regarding unsafe 
and safe abortions, indicating that mortality rates due to unsafe abortions are likely to be underestimated [29, 30].

Globally, it is crucial to prevent repeat UPs, through the promotion of effective contraception, when seeking to improve women's SRHR [27, 28, 31]. UPs involve both unplanned and unwanted pregnancies and unplanned births, induced abortions, and miscarriages resulting from unintended pregnancies [32]. In this thesis, the term UP includes both unplanned and unwanted pregnancies in the context of an abortion.

Access to effective contraception has wide benefits for women, beyond the prevention of UPs and abortions [5, 27]. The use of effective contraception also prevents unintended pregnancy- related events, such as miscarriages and ectopic pregnancies [7, 33]. Furthermore, contraceptive use prevents complications such as haemorrhage, sepsis and incomplete abortions related to both safe and unsafe abortions $[5,28$, 30].

The majority of unsafe abortions occur in countries with highly restrictive abortion laws [29], where many women also have limited or no access to contraceptives [34, 35]. Young unmarried women describe few possibilities to control their reproduction as they experience stigma when applying for contraceptives [20, 27, 35].

In contrast, women who have access to contraceptives struggle to find a satisfying and effective contraceptive method, reflected in high rates of repeat abortions (39-50\%) in countries like Sweden, the USA and UK [36-40]. Sweden is one of the countries in Europe with the highest recorded rates of repeat abortions [36]. Repeat abortion is defined as more than one pregnancy termination $[41,42]$ and is associated with one 
or more childbirths $[38,41]$, older age [38], as well as young age at the first abortion or pregnancy [12, 41].

Worldwide, repeat UPs and abortions are strongly associated with socioeconomic challenges and inequalities in SRHR, identified in migrant groups, ethnic minorities, and deprived areas [9, 11, 12, 38, 40, 43-45]. These women choose less effective contraceptives or no contraception to a greater extent [46-49] and report more negative experiences from contraceptive counselling, according to contexts in the USA [50-52]. Research from different countries indicates that the risk of repeat abortion increases with lower educational attainment [11, 13, 43, 53], foreign origin [38, 44], low emotional support [13] and experiences of sexual violence $[9,54]$. Women who experience more than one abortion within two years seem to have an increased vulnerability, reporting both intimate violence, social deprivation, and difficulties in finding a contraceptive method [54]. Overall, women's vulnerability and negative experiences of contraceptive counselling indicate a need to improve counselling to strengthen women's control over their reproduction.

Moreover, it is important to strengthen women's control over their reproduction and prevent repeat UPs, since an UP is often a stressful event in a woman's life [16, 55-57]. Emotional distress is common when discovering an UP, as well as desperate feelings when being denied an abortion $[16,55,58]$. There is still an inadequate understanding of how contraceptive counselling and services should be designed to facilitate women's individual needs for support and contraception at the time of an abortion in order to prevent repeat UPs [19, 59]. 


\section{Contraceptive counselling at the time of an abortion}

In general, there are many definitions of counselling. In healthcare settings, it is described as a collaborative process during which a health professional (HP) guides clients to manage their health and identify individual resources. Counselling involves a professional relationship between a trained HP and a client [6o]. Contraceptive counselling is described as a process in which the goal is to empower women to prevent UPs [61]. Furthermore, contraceptive counselling involves both relational and informational communication $[61,62]$ and both of these seem to be important for successful counselling [63].

The importance of relational communication seems slightly dominant in the context of an abortion [15, 19,64] and stresses need of individualised contraceptive counselling [19, 59]. Women's use of contraception varies over time and is related to complex factors such as: sexual relationships [65], intentions in pregnancy [66, 67], estimation of fertility [25, 68, 69] and experiences of side effects [19, 65, 68, 70]. Other factors, like education $[27,66]$, age, parity $[67,71]$, cost, religion, culture and access to contraceptive services $[25,27]$ also influence women's choice and use of contraceptives.

Women favour trusting relationships when receiving contraceptive advice and seem to prefer person-centred contraceptive counselling [15, 72]. Both motivational interviewing (MI) and person-centred counselling seem to improve the conversation about contraception at the time of an abortion, measured in increased contraceptive uptake [72, 73]. Previous research has reported mixed findings regarding contraceptive counselling in the context of an abortion and the effect on contraceptive use post- 
abortion. Few studies have explored the impact of person-centred counselling or MI at the time of an abortion in clinical practice $[17,18,72$, 73].

Regarding informational communication, studies in several countries indicate that information and knowledge about side effects and effectiveness are fundamental when women choose contraceptives [25, $65,68,74-77]$, including at the time of an abortion [15, 72, 73]. Informational communication concerning effectiveness and side effects presented via visual decision aids seems to facilitate women's contraceptive choices [73, 78].

Information regarding side effect also seems to be central in counselling since it is common for women to discontinue contraceptive use due to experiences and fear of side effects [25, 68, 69]. Side effects that trouble women are effects on mood [70], weight gain, and changes in menstrual patterns [76]. Fear of side effects seems to also negatively influence women's contraceptive use after an abortion [79-81]. On the other hand, women are also reported to be more willing to initiate contraceptive use post-abortion. However, research indicates mixed findings regarding women's motivation for contraceptive use after an abortion [2, 3, 82].

The time of an abortion is described as crucial for women to find and initiate a satisfying contraceptive method [2], especially, since they may choose not to return for a follow up [41] or may not have the opportunity to do so due to long distances, stigma or violent relationships [2, 28]. Women's fertility also returns quickly post-abortion [83, 84], and 60\% of women have intercourse within two weeks, according to a Swedish study [85]. 
Previous research indicates that women find contraceptive counselling practical and feasible at the time of abortion counselling if it is provided in a non-judgemental manner $[14,86]$. On the other hand, this counselling seems to be different from contraceptive consultations in general. Contraceptive counselling at the time of abortion often includes multifaceted and existential abortion decisions for women and their partners $[16,55]$, and hence women seem to have a limited receptivity to information about contraceptives [14].

Feelings of anxiety and ambivalence are common at the time of an abortion. In contrast, women also express feelings of relief, higher levels of quality of life and increased maturity after an abortion [55-57]. Women who experience an abortion appear to have higher psychiatric morbidity compared with women who do not $[87,88]$. Experiences of abortion are not associated with increased risk of psychiatric morbidity, according to previous studies. Instead psychiatric morbidity seems to already exist in women before the abortion, and to increase the likelihood of abortion. A higher psychiatric morbidity among women who experience an abortion may thus reflect increased vulnerability $[58,89]$. These women may have increased needs for follow up and for trusting relationships in counselling.

Women report feelings of being pushed to choose a more effective method, such as long-acting reversible contraception (LARC), and experiences of stigma at the time of a repeat abortion [90, 91]. This may negatively affect their ability to establish trusting relationships [50, 64, 92], especially at the time of an abortion [64].

There is still insufficient knowledge about how trusting contraceptive counselling in relation to abortion counselling influences and contributes to more effectively preventing repeat UPs and abortions. This emphasises 
the need to understand women's and HPs' views on contraceptive counselling at the same time as abortion counselling. Few studies report on women's lived experiences of contraceptive counselling following abortion counselling and its influence on contraceptive use post-abortion $[14,17,18]$.

\section{Prevalence of contraceptive use}

Globally, contraceptive use has increased since 1970. About $63 \%$ of married women of reproductive age were using modern or traditional methods of contraception in 2017. Contraceptive use is still lower in Africa (36\%) compared to other major regions of the world [93]. The combined oral contraceptive (COC), intrauterine devices (IUDs) and female sterilisation are cited as the most commonly used female contraceptive methods [26, 94]. Male contraceptive methods or methods that require their co-operation to use, account for one-quarter of all contraceptive use globally and include condoms, withdrawal, rhythm and male sterilisation [94].

The contraceptive pattern has changed in the USA and Scandinavian countries like Sweden, Denmark and Finland. More women choose LARC [70, 95, 96], which is collectively defined as IUDs, Levonorgestrelintrauterine systems (LNG-IUSs), and subdermal implants [96]. In Sweden, approximately $40 \%$ of fertile women use hormonal contraceptive methods [96]. Swedish women who have given birth have a long tradition of using IUDs/LNG-IUSs [71]. COC, IUDs and LNG-IUSs are the most commonly used methods in Sweden [96]. Globally, COC seems to be the most commonly chosen method after an abortion [2, 3, 82], but less is known regarding Swedish women's contraceptive choices at that time. 
Many UPs occur despite contraceptive use, which may be due to women and HPs overestimating the effectiveness of different contraceptive methods [7, 97], contraceptive failure [8, 98] or discontinuation [67]. The effectiveness of a contraceptive method is measured by the Pearl Index, which indicates how many pregnancies occur per 100 women's years when using a specific method. The Pearl Index is related to both method error and user error [99]. For example, COCs are theoretically effective in preventing UPs, but due to contraceptive failure such as forgetfulness, the effectiveness decreases [97]. Women's adherence to treatment does not seem to differ between 28-day use, extended or continuous cycles, when comparing different regimens of using COC, the ring and the patch [100].

In contrast to COC, LARC are independent of daily habits or use in direct relation to intercourse. These methods lack user error, which means that the actual efficiency is largely equivalent to the theoretical efficiency [97, 101]. Women seem more satisfied and continue to a larger extent when using LARC compared to COC after a year [102]. On the other hand, many women who use $\mathrm{COC}$, benefit from important reductions of endometrial, ovarian, and colorectal cancer risk that persist for many years after discontinuing [103].

Use of LARC shows a significantly lower risk of UPs and repeat abortion within a period of two to four years after abortion, compared to use of COC or condoms. However, few of the studies include longer follow up times or the choice of subdermal implants after an abortion [41, 104, 105]. Regarding the use of LARC at the time of an abortion, a subdermal implant can be inserted at the time of a medical abortion at mifepristone intake or during a surgical abortion [106, 107]. An IUD/ LNG-IUS can be inserted directly after surgical abortion or within 10 days post medical abortion [85]. Immediate insertion of an IUD/LNG-IUS seems to increase 
contraceptive uptake compared to insertion four weeks post-abortion, since more women return within 10 days [85]. In Sweden, if women wish to use LARC, insertion has generally been undertaken three to four weeks after a medical abortion or directly after a surgical abortion [108]. According to recent recommendations, LARC methods should be provided and inserted within a week post medical and surgical abortion [109]. However, studies evaluating early insertion of LARCs in clinical practice in the context of abortion are sparse.

\section{Contraceptive and abortion care in Sweden}

According to the Swedish goals for SRHR, all women and men should have access to knowledge about effective contraceptive methods [6, 110]. In the Swedish health care system, contraceptive counselling is free of charge to women of all ages. A number of hormonal contraceptives are subsidised for women up to the age of 25 years, including subdermal implants and LNG-IUS [111]. Contraceptive counselling and prescriptions for contraceptives are mostly provided by midwives in the primary healthcare service and at youth clinics [112]. Women who need extra control in relation to diseases should be referred to a gynaecologist for contraceptive counselling [99].

According to Swedish abortion law, contraceptive counselling should be offered at the time of an abortion, as well as counselling with a social worker [113]. The main professionals involved in the abortion care are gynaecologists, midwives, nurses and social workers [109]. Women are free to undertake an abortion until the 18th week of pregnancy (week $18+0$ days [114]. Medical abortions represent 93\% of all abortions; $75 \%$ of all abortions are performed at home, before gestational week nine. In comparison, surgical abortion was the most common method during the 
1990s. Today, only $7 \%$ of all abortions are surgical and the majority of these are undertaken in gestational weeks 9-12+o [36].

There are about 37000 induced abortions each year in Sweden, almost 20 per 1000 women in the age range of 15-49 years. Abortions among teenagers have decreased from 25 per 1000 women in 2006 to 12 per 1000 women in 2017. However, the rate of repeat abortions (45\%) has increased [36], although this rate is unclear, despite previously described conditions. There is no national abortion register based on Swedish personal identification numbers that would enable research on women's choice of contraceptive methods or an evaluation of the prevention of repeat UPs and abortions [115].

At the time of an abortion, both midwives and gynaecologists provide abortion and contraceptive services, including counselling and the insertion of LARC. Gynaecologists are formally responsible for the abortion service. Specially educated and delegated midwives run services for early medical termination of pregnancy autonomously, including counselling, examination, ultrasound and treatment [108].

\section{To improve contraceptive counselling and services in abortion care}

Given the challenges with repeat UPs outlined above, there is room for improvement in abortion services. Improvement follows from the application of knowledge through changing how work is carried out [116, 117]. In abortion care, the question is how midwives, gynaecologists and other HPs might change their approach to contraceptive counselling and services to better enable their patients to prevent repeat UPs.

Previous research shows the difficulty of implementing new knowledge and changing clinical practice [118]. Implementation is described as a 
process of integrating new practice in settings. There are several models and theories in implementation science describing and/or explaining as well as evaluating the process [119]. There are similarities between implementation science and systematic quality improvement studies as both involve the process of changing clinical practice. However, a quality improvement study in health care also describes the effects of improvement actions and health related outcomes in the health research context [120].

Many healthcare organisations undertake systematic quality improvement efforts to facilitate changes in clinical practice [121]. One approach is Quality Improvement Collaborations (QICs), such as the Breakthrough collaborative model [122]. A number of teams come together around an issue of common interest to decrease the gap between existing knowledge and regular clinical practice, in order to improve people's health and health care [122, 123]. QICs involve the use of quality improvement methods [122] and are widely used in health services [123125]; they have also been tried in contraceptive services [126]. Previous research regarding contraceptive services indicates that a QIC approach can help to improve the quality of contraceptive services [126]. Less is known regarding QICs and user involvement for improving contraceptive counselling and services in abortion care.

When aiming to improve health care services, there is growing support for the benefits of collaborating with patients $[127,128]$. User involvement is thought to improve partnerships and services in healthcare [127, 129]. User involvement can also mean that patients are actively involved in research projects. Patients who are involved as partners in research share their experiences of healthcare and both participate and collaborate in the design and reporting of research [128]. This thesis employed user involvement in the QIC in study IV through the voluntary contributions of 
two women with lived experience of contraceptive counselling at the time of abortion.

\section{Theoretical framework}

The concepts of prevention, health promotion and person-centred care formed the theoretical framework for this thesis. The research process considered the concepts of prevention and health promotion as central aspects of SRHR [5] and contraceptive counselling [61] in the context of abortion. During the research process, the principle of person-centred care [130-132] became a part of the theoretical framework.

\section{Prevention and health promotion}

Prevention is defined as keeping people away from unwanted events, such as diseases, physical damages and social problems [133, 134]. Prevention that includes an entire population is called universal prevention, while prevention intended for a particular group of the population is called selective prevention. Indicated prevention is intended for individuals who have an increased risk of an undesired event. Prevention of UPs involves all three - universal, selective and indicated - approaches [134]. Universal prevention could include strengthening knowledge about contraceptive methods among both women and men to prevent UPs. Additionally, women who experience abortions are believed to be a group that needs selective and indicated prevention to avoid a repeat UP.

The concept of health promotion is closely related to prevention, and these concepts overlap and share many goals. Health promotion is described as a process of empowering people to take control of their own health and to improve healthy behaviours among individuals and communities [133]. 
Developing information, access to contraceptive methods and strategies in counselling to strengthen SRHR are health-promoting activities [133]. These activities can also be defined as prevention when aiming to prevent repeat UPs and abortions [5]. In this thesis, health-promoting activities and prevention are also described as drivers or improvement actions.

Preventing UPs is complex; what works for one woman or one country does not necessarily work for other women or countries [135, 136]. Previous prevention programmes have reported an increased choice of LARCs among women with socioeconomic challenges in the USA [136], whereas there was limited impact on women's contraceptive choices in a similar setting in the UK [135]. The core message in health promotion and prevention programmes might interfere with people's autonomy and cause resistance to such things as more effective contraceptive methods, such as LARC [92, 137]. Women may experience infringement of their reproductive autonomy at the time of contraceptive counselling, even in countries where contraception is promoted, accepted and available [64, 92]. This indicates that healthcare services aimed at preventing UPs need to be designed in line with women's autonomy and individual needs. Furthermore, the services and counselling need to enable and strengthen women to prevent UPs. One way of achieving this is to develop counselling inspired by person-centred care.

\section{Person-centred care}

There is a growing knowledge regarding the value of person-centred care (PCC) when meeting with patients and improving healthcare services [130]. For PCC to be facilitated in clinical practice, it needs to be applied consistently at all levels of healthcare. Health services need to develop practices that integrate and maintain PCC in daily clinical work [131, 132, 138]. 
Improving the partnership between HPs and the patient is central in PCC. The patient is seen as an equal partner, a human being and an expert in his or her own situation, and is given the opportunity to be active in planning the healthcare [131]. The concept involves empathy, respect and active listening to the patient's story. PCC also includes developing the partnership, e.g. through shared decision-making (SDM), and involves a mutually agreed plan for the care. The plan includes coordinated care or treatment [130, 132, 138].

The concepts of PCC and patient-centred care have many similarities [139]. Both concepts focus on empathy, respect and engagement when building a relationship with the patient. However, there seem to be differences regarding the goals [139]. PCC seems to focus more on the meaning of life and emphasises the importance of understanding the person behind the patient in order to engage the person in their care [131, 139].

PCC involves different approaches due to the clinical situation. SDM and MI are examples of useful and well-described approaches to achieving PCC in situations where knowledge supports specific behaviour changes [140]. Both approaches focus on the person's values, needs, and resources, and involve reflective listening to women's stories and openended inquiry [62, 72, 73, 141]. SDM focuses on making a decision and $\mathrm{MI}$ on the process of changing a behaviour [140].

Strengthening the person's autonomy is central in SDM. The HP's role is to support people to become well-informed. The role also includes supporting individuals in exploring their personal preferences among available choices and providing professional guidance in their decisionmaking [140]. In MI, the HP focuses on supporting people to recognise their own abilities and to resolve ambivalence about changing their 
behaviour. It is often practised in situations that require behaviour change that a person feels ambivalent about [140, 142]. However, many clinical consultations seem to involve both MI and SDM [140].

When practising SDM at the time of contraceptive counselling, the HP presents contraceptive options, including information about side effects and effectiveness. The HP should also provide opportunities for women to express their fears as well as ask questions about contraceptives and interactively participate with the woman in method selection [62].

PCC and SDM have been criticised since some people may have no or little ability to participate in decisions regarding their own health. It has also been discussed in terms of the likelihood of having an equal partnership in healthcare. On the other hand, PCC should cover a holistic perspective, including individuals' complex needs [143] and ability to coproduce health [129]. SDM should be seen as a dynamic process between paternalism and the client's informed choice in clinical settings. In situations where the HP and client do not agree, SDM seems to provide an approach for conflict resolution that can be valuable from an ethical perspective [144].

\section{Rationale}

A high proportion of women who have experienced an abortion undergo repeat UPs [36, 39], despite contraceptive use and/or access to contraception [98]. It is still unclear how to design and improve contraceptive counselling at the time of an abortion in order to support women to prevent repeat UPs $[17,18]$. Repeat UPs and abortions are associated with socioeconomic challenges $[9,12,38]$ and thus indicate health inequalities amongst women. This stresses the need to support women to recognise their own abilities, expand their knowledge and their 
autonomy in contraceptive decision-making. Thus strengthening women's ability to choose and initiate a contraceptive method that prevents UPs would help increase their SRHR.

One possibility is to generate additional research evidence on the effectiveness of different contraceptive methods post-abortion in order to increase knowledge about how to support women in preventing a repeat UP in clinical practice. Previous studies are performed under strictly controlled conditions; few studies regarding LARC are consistently applied in clinical practice [41, 104, 145].

Another central opportunity is to develop knowledge about how to provide contraceptive counselling that fulfils women's needs at the time of an abortion. It is essential to understand women's lived experiences since they report limited trust in HPs in contraceptive decision-making [50, 65, 92]. Women might have other needs in complicated life situations that it is important for HPs to take into account [13, 19, 54]. To date, the research on women's lived experiences of contraceptive counselling at the same time as abortion counselling and their influence on contraceptive use post-abortion is scanty $[14,19,86]$.

Filling the aforementioned knowledge gap can be seen as the first steps in seeking to design and improve contraceptive counselling and services in abortion care. Little is known regarding the benefits of applying the principles of PCC [130, 138], and user involvement [127] in clinical practice and quality improvement models such as QIC, when improving contraceptive counselling at the time of an abortion [122, 123]. 


\section{AIMS}

The overall aim was to study women's choice and use of contraceptive methods post-abortion. The research also aimed to describe contraceptive counselling in the context of an abortion from women's and HPs' perspectives. Initial studies informed subsequent improvement efforts, also evaluated in the thesis, regarding contraceptive counselling and services at the time of an abortion.

Specific aims

To study the choice of contraceptive method after abortion and the related odds of repeat abortions within three to four years (study I).

To identify and understand women's lived experiences of contraceptive counselling given at the same time as abortion counselling (study II).

To identify and describe HPs' experiences of providing contraceptive counselling to women seeking an abortion (study III).

To describe and evaluate a QIC designed to enhance contraceptive services, with regard to changes in HPs' counselling in clinical practice and in women's subsequent choice of, and access to contraception (study IV). 


\section{METHOD}

\section{Designs and settings}

In this thesis, a variety of methods were used in order to explore several aspects of contraceptive counselling and services at the time of an abortion and increase our understanding [146, 147].

In study I, a quantitative approach was used. Numerical data was collected from medical records at the time of an abortion and analysed. Studies II and III took qualitative perspectives, whereby interviews provided an understanding of contraceptive counselling and services at the time of an abortion. Study IV invited multi-professional teams to apply knowledge generated in studies I-III in a QIC emulating the Breakthrough Collaborative model [122]. Furthermore, study IV combined quantitative and qualitative perspectives in a case study design to document and evaluate efforts to improve counselling and services. Numerical data from medical records regarding contraceptive choice and use were collected and analysed, along with project documentation regarding HPs' experiences of the QIC. See Table 1 for an overview of the designs and settings of the studies.

In total, six hospitals in departments of obstetrics and gynaecology were involved in studies I-IV. These six hospitals were differently sized and located in two counties in the south-east of Sweden. In three departments, both gynaecologists and specially trained midwives provided early medical abortion services, whereas in the other three only gynaecologists provided abortion services, at the time of data collection. The two counties exhibited different rates of repeat abortions, $38-52 \%$ and were diverse sociodemographically [148]. 
Table 1. Overview of the studies included in the thesis

\begin{tabular}{|c|c|c|c|c|c|}
\hline Study & Design & $\begin{array}{l}\text { Participants/ } \\
\text { sample }\end{array}$ & Setting & $\begin{array}{l}\text { Data } \\
\text { collection }\end{array}$ & Analyses \\
\hline I & $\begin{array}{l}\text { Quantitative } \\
\text { prospective } \\
\text { cohort study }\end{array}$ & $\begin{array}{l}987 \text { medical } \\
\text { records of women } \\
\text { undergoing } \\
\text { abortion }\end{array}$ & $\begin{array}{l}\text { University } \\
\text { hospital (1) } \\
\text { Central county } \\
\text { hospital (1) } \\
\text { District hospital (1) }\end{array}$ & $\begin{array}{l}\text { Review of } \\
\text { medical records } \\
\text { during } \\
\text { 2009-2012 }\end{array}$ & $\begin{array}{l}\text { Parametric and } \\
\text { non-parametric } \\
\text { analyses } \\
\text { Chi-square, } \\
\text { Students' T-test, } \\
\text { Survival analysis, } \\
\text { Regression model, }\end{array}$ \\
\hline II & $\begin{array}{l}\text { Qualitative } \\
\text { inductive } \\
\text { interview study }\end{array}$ & $\begin{array}{l}13 \text { women who } \\
\text { had experienced } \\
\text { an abortion }\end{array}$ & $\begin{array}{l}\text { University } \\
\text { hospital (1) } \\
\text { Central county } \\
\text { hospital (2) } \\
\text { District hospitals (2) }\end{array}$ & \begin{tabular}{|l|} 
Individual \\
interviews
\end{tabular} & $\begin{array}{l}\text { Interpretive } \\
\text { phenomenology }\end{array}$ \\
\hline III & $\begin{array}{l}\text { Qualitative } \\
\text { inductive } \\
\text { interview study }\end{array}$ & $\begin{array}{l}6 \text { midwives and } \\
15 \text { gynaecologists }\end{array}$ & $\begin{array}{l}\text { University } \\
\text { hospital (1) } \\
\text { Central county } \\
\text { hospital (1) } \\
\text { District hospital (1) }\end{array}$ & $\begin{array}{l}\text { Individual } \\
\text { interviews }\end{array}$ & $\begin{array}{l}\text { Qualitative } \\
\text { conventional } \\
\text { content analysis }\end{array}$ \\
\hline IV & $\begin{array}{l}\text { Organisational } \\
\text { case study } \\
\text { regarding a QIC }\end{array}$ & $\begin{array}{l}\text { Three teams } \\
\text { involving } 13 \\
\text { professionals in } \\
\text { abortion care }\end{array}$ & $\begin{array}{l}\text { Departments of } \\
\text { Gynaecology and } \\
\text { Obstetrics at } \\
\text { Central county } \\
\text { hospitals (2) and } \\
\text { District hospital (1) }\end{array}$ & $\begin{array}{l}\text { Quantitative } \\
\text { data } \\
\text { Qualitative } \\
\text { data }\end{array}$ & $\begin{array}{l}\text { Statistical process } \\
\text { control chart } \\
\text { analysis } \\
\text { Content analysis }\end{array}$ \\
\hline
\end{tabular}




\section{Samples and characteristics of participants}

\section{Study I}

All women with a Social Security Number (i.e. permanent residents of Sweden) who had a diagnosis of 'unwanted pregnancy' (z.64.0 in ICD-10) during 2009, at the three hospitals were included (Table 1). Women were excluded if they moved out of the catchment area, if the diagnosis at the index visit was incorrect, if women decided to continue the pregnancy, or if sterilisation or hysterectomy occurred during the follow-up period (Figure 1). Furthermore, women were also excluded if the induced abortion was due to maternal illness or foetal abnormalities, since these women might desire a pregnancy in the near future.

In power calculations, we hypothesised that the choice of LARC postabortion would be related to fewer repeat abortions within three to four years compared with other contraceptive choices. We needed to include 705 women (medical records), to reach $80 \%$ power, to identify a difference at a 0.05 significance level. We expected that $30 \%$ of the women would choose LARC [41] but there was a substantial uncertainty in this approximation; therefore, we doubled the number of women.

A total of 1574 medical records of women had a diagnosis of unwanted pregnancy (z.64.o. in ICD-10). In this group, we recognised 1395 women who had undergone an abortion during 2009 at the study hospitals. Of these 1395 medical records of women, 587 were excluded (Figure 1). Background characteristics of the women in study I are described in Table 2. 


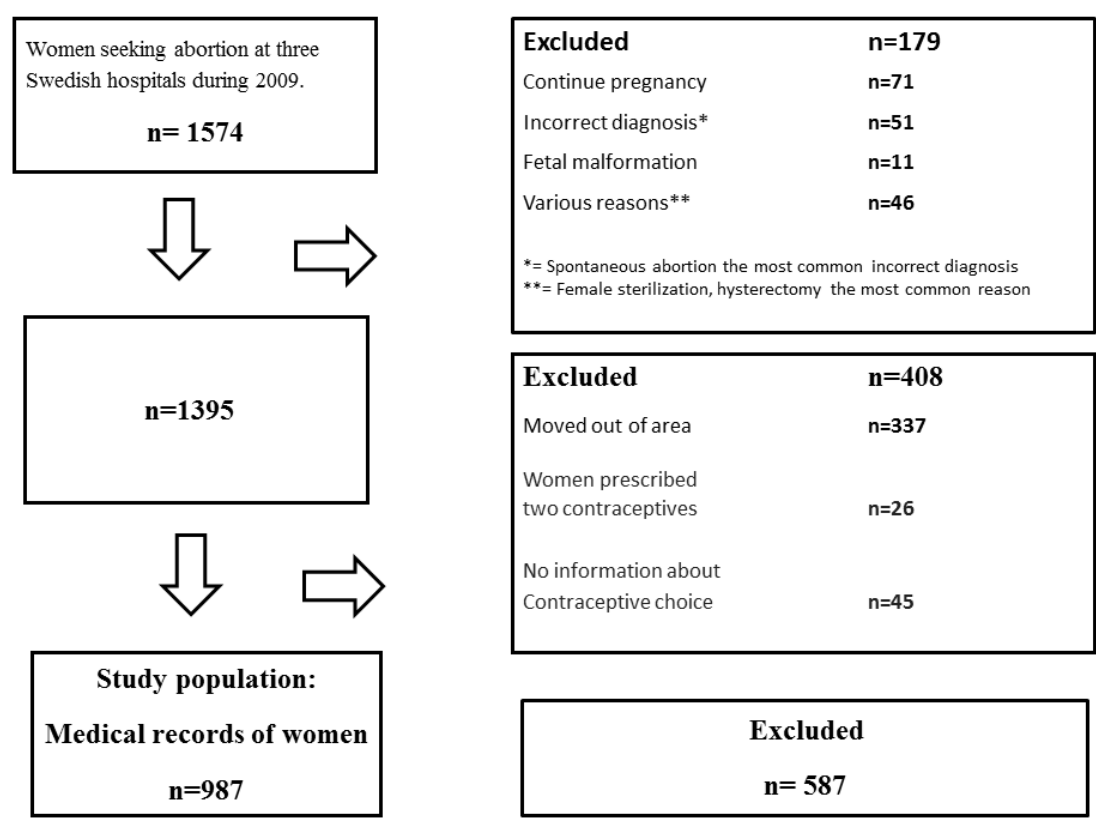

Figure 1. Flowchart of included medical records.

\section{Studies II and III}

To achieve a wide range of experiences in the interview studies, we included women and HPs from different counties and from differently sized hospitals (Table 1).

In study II, 29 Swedish-speaking women, >18 years old who had undergone an abortion, were invited to participate in the study. Sixteen declined to participate and 13 women were interviewed. Women were excluded if the termination of pregnancy followed because of foetal malformations or a maternal disorder. Background characteristics of the interviewed women are described in Table 2. In addition, four were single and two women stated mental health problems. 
In study III, 40 HPs, who were providing contraceptive counselling and prescribing contraceptives within abortion care, were invited to participate. Twenty-four agreed to participate. Three were excluded as they were not presently prescribing contraceptives in the context of an abortion. Finally, 21 HPs were interviewed. Characteristics of the interviewed HPs are described in Table 2. Additionally, the HPs had a median of 10 years of professional experience (range 1-21) and two of the HPs were male. In this thesis, HPs are subsequently defined as gynaecologists and midwives providing contraceptive counselling and services within abortion care. 
Table 2. Characteristics of participants in studies I-IV

\begin{tabular}{|l|l|l|l|l|}
\hline Study & I & II & III & IV \\
\hline $\begin{array}{l}\text { Participants } \\
\mathrm{n}\end{array}$ & $\begin{array}{l}\text { Women } \\
987\end{array}$ & $\begin{array}{l}\text { Women } \\
13\end{array}$ & $\begin{array}{l}\text { HPs } \\
21\end{array}$ & $\begin{array}{l}\text { Professionals } \\
13\end{array}$ \\
\hline $\begin{array}{l}\text { Age } \\
\text { median } \\
\text { (range) }\end{array}$ & 26 & 27 \\
$(14-54)$ & $\begin{array}{l}20-40) \\
\left(\begin{array}{l}\text { Previous pregnancy } \\
\text { n/\% }\end{array}\right.\end{array}$ & $\begin{array}{l}42 \\
(30-64)\end{array}$ & \\
\hline $\begin{array}{l}\text { Previous birth } \\
\text { n/\% }\end{array}$ & $619 / 63$ & $10-$ & - & - \\
\hline $\begin{array}{l}\text { Previous abortion } \\
\text { n/\% }\end{array}$ & $548 / 55$ & $6-$ & - & - \\
\hline $\begin{array}{l}\text { Education: } \\
\text { highest attained }\end{array}$ & $380 / 38$ & $5-$ & - & - \\
\hline $\begin{array}{l}\text { Upper secondary } \\
\text { school }\end{array}$ & - & 8 & - & 2 \\
\hline University & - & 5 & 21 & 11 \\
\hline Profession & & & & \\
\hline Midwife & - & - & 6 & 7 \\
\hline Gynaecologist & - & - & 15 & 2 \\
\hline Social worker & - & - & - & 2 \\
\hline Secretary & - & - & - & 2 \\
\hline
\end{tabular}

${ }^{*} \mathrm{HPs}=$ Health professionals. Gynaecologists and midwives providing contraceptive counselling and services within abortion care. 


\section{Study IV}

Departments of obstetrics and gynaecology at three hospitals agreed to send teams to participate in a QIC (Table 1). Participating departments were guided to form multi-professional teams including 4-5 professionals involved in abortion care (Table 2). In two of these departments, both gynaecologists and midwives provided medical abortion, whereas in the third department, only gynaecologists did so (team C).

\section{Procedure and data collection}

\section{Study I}

Medical records were reviewed manually from the date of the index abortion during 2009 until 31 December 2012, by using a standardised form. Local secretaries in each department de-identified all records before three reviewers (the author and three researchers in the researcher group) started the record review and data collection. The standardised form and review procedure were pilot tested on 30 records, which led to a few changes. Subsequently, the 30 pilot medical records were included in the study.

The three reviewers had a referee in case of inquiries or disparities. Data collected from the medical records are presented in Table 3. Data regarding women's choice of contraceptive method was collected within four weeks after the index abortion. If the woman chose no contraception, it was documented as "No chosen method". LARC was defined as $\mathrm{Cu}$ IUDs, LNG-IUS and sub-dermal implants. Repeat abortion was defined as one or more pregnancy terminations during the follow-up time. At each hospital, each woman's record was reviewed for repeat abortions from the time of the index abortion until the end of 2012. We were not able to trace women outside the region of their hospital in Sweden as there is no individual-based abortion register. 
Table 3. Overview of data collection for studies I-III

\begin{tabular}{|c|c|c|}
\hline Study I & \multicolumn{2}{|l|}{ Studies II and III } \\
\hline $\begin{array}{l}\text { Quantitative } \\
\text { retrospective } \\
\text { cohort study }\end{array}$ & \multicolumn{2}{|c|}{ Qualitative inductive interview study } \\
\hline $\begin{array}{l}\text { Data } \\
\text { from records: }\end{array}$ & II Main question & $\begin{array}{l}\text { III Semi-structured } \\
\text { interview guide }\end{array}$ \\
\hline $\begin{array}{l}\text { Age } \\
\text { Previous } \\
\text { Pregnancies } \\
\text { Deliveries } \\
\text { Abortions }\end{array}$ & $\begin{array}{l}\text { "Please tell me } \\
\text { about the meeting } \\
\text { where you talked about } \\
\text { the abortion } \\
\text { and contraceptives?" }\end{array}$ & $\begin{array}{l}\text { "Please tell me how } \\
\text { you think about } \\
\text { contraceptive methods } \\
\text { for a woman seeking } \\
\text { abortion?" }\end{array}$ \\
\hline $\begin{array}{l}\text { Choice of } \\
\text { contraceptive } \\
\text { method at the } \\
\text { index abortion } \\
\text { Abortion } \\
\text { method }\end{array}$ & & $\begin{array}{l}\text { How do you reason } \\
\text { about adherence when } \\
\text { prescribing a certain } \\
\text { contraceptive to } \\
\text { a woman? }\end{array}$ \\
\hline $\begin{array}{l}\text { Use of } \\
\text { interpreter } \\
\text { Current } \\
\text { Chlamydia } \\
\text { infection }\end{array}$ & & $\begin{array}{l}\text { What do you do if a } \\
\text { woman is hesitant } \\
\quad \text { about using contraception? } \\
\text { (When meeting a } \\
\text { woman) }\end{array}$ \\
\hline \multirow{4}{*}{$\begin{array}{l}\text { Repeat abortion } \\
\text { during the period } \\
2009-2012\end{array}$} & Probes/follow & questions \\
\hline & $\begin{array}{l}\text { Can you please tell me } \\
\text { Can you give an exampl }\end{array}$ & \\
\hline & Demographics & \\
\hline & $\begin{array}{l}\text { II } \\
\text { Age } \\
\text { Highest education } \\
\text { Relationship status } \\
\text { Employment status } \\
\text { Reproductive history } \\
\text { Choice of } \\
\text { Contraception at: } \\
\text {-unintended conception } \\
\text {-at the abortion }\end{array}$ & $\begin{array}{l}\text { III } \\
\text { Age } \\
\text { Gender } \\
\text { Profession } \\
\text { Years of professional } \\
\text { experience }\end{array}$ \\
\hline
\end{tabular}




\section{Studies II and III}

In study II, women were invited to the study by midwives and gynaecologists who met them during abortion counselling. The women were invited for an interview four to six weeks post-abortion. In study III, midwives and gynaecologists (HPs) involved in contraceptive prescription and counselling in the abortion care were invited through staff meetings or via mail. Women and HPs who agreed to share their experiences were contacted via telephone or e-mail by the author (HK) and orally informed about the study.

In both studies, pilot interviews were conducted to test the interview questions. The material from the pilot interview in study II was included in the analysis, because it was valued as rich information. All the interviews were initiated with an open-ended request (study II) or by interview questions, not necessarily in the same order (study III). In both studies, follow-up questions and probes were used to generate a deep understanding of their experiences (Table 3).

The interviews were performed by $\mathrm{HK}$ at places and times chosen by the women and HPs between May 2016 and January 2017 (study II) and between June 2014 and January 2015 (study III). Furthermore, the interviews were conducted in private homes, in private rooms at libraries, work-places or through web-based communication (Skype ${ }^{\circledR}$ ) [149].

The median duration of the interviews was 49 min (29-65 min) (study II), and 40 min (25-62 min) (study III). The interviews (studies II and III) were digitally recorded, de-identified, transcribed verbatim and kept in a locked place. 


\section{Study IV}

This study was a case study regarding a QIC [150], performed as part of regular health services, involving three multi-professional teams. Before the QIC (October-December 2016), two researchers visited staff meetings in the teams' departments. Each team and their department head were informed of the findings from studies I-III through staff meetings. Team members agreed to share de-identified data regarding women's choice of contraceptives and start of LARC at the time of an abortion with the research team. They also gave informed consent for researchers to take field notes of observations from the QIC. The QIC included four Learning Sessions (LSs), during March-November 2017 (Figure 2). Two women with personal experiences of contraceptive counselling in the context of an abortion (who had participated in study II) agreed to give feedback on the team's ideas as a form of user involvement [127] to help the teams to improve their counselling and services. 


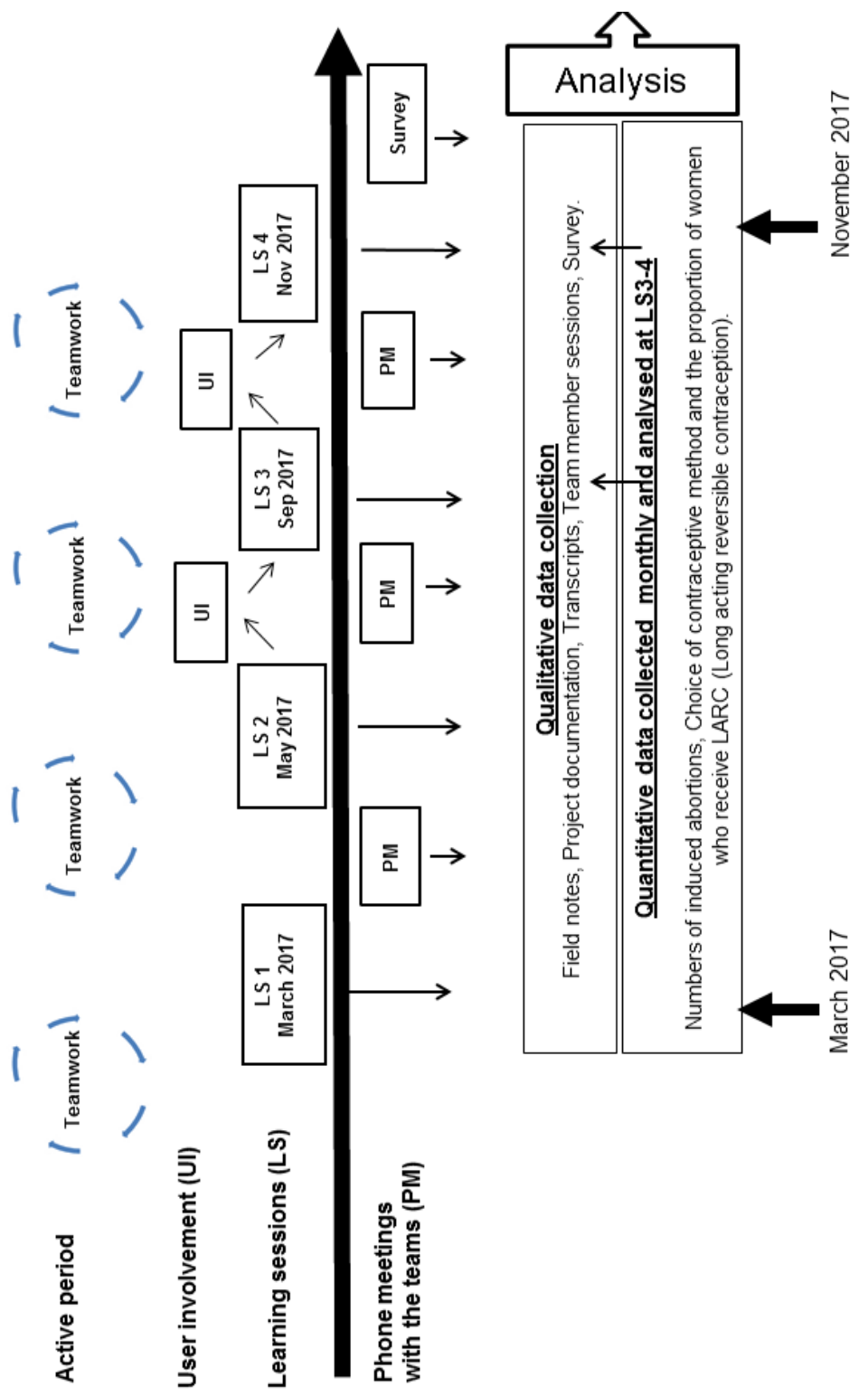

Figure 2. Timeline for the case study design regarding a Qualitative Improvement Collaborative (QIC) $\mathrm{PM}=$ Phone meetings, $\mathrm{LS}=$ Learning sessions, $\mathrm{UI}=$ User involvement 
An external Improvement Advisor, from one of the participating health systems, supported the teams in using improvement tools, including the Driver diagram, the Action plan and the PDSA (for Plan, Do, Study and Act) cycle [116]. During "Active periods" between LSs (Figure 2), the teams planned, tested and studied changes in practice - improvement ideas - in their own departments. Each team was asked to appoint a coordinator, to link the team with the Improvement Advisor and the researcher (HK) during the QIC.

The case study combined the collection of both qualitative and quantitative data to describe how the QIC developed (Figure 2). Qualitative data included field notes, taken by the researchers, and project documentation including HK's e-mail correspondence throughout the QIC and notes from phone conversations. It also involved verbatim transcripts of a group session during the concluding LS4 with team members involved in counselling. Furthermore, data were collected through an anonymous electronic survey, sent out by the Improvement Advisor to team members, regarding their experience of participating in the QIC.

Quantitative data included:

- The number of induced abortions at the three departments per month during the QIC

- The monthly proportions of different contraceptive methods chosen by women at the time of an abortion as documented in the medical record

- The monthly proportions of women who started to use LARC within 30 days post-abortion.

The time of an abortion was defined as the day of mifepristone-intake or the day of surgical abortion (O04.9 a-x in ICD-10). Women who 
experienced abortion related to foetal malformations were excluded from the analyses. From May to October 2017, the administrator in each team manually collected and de-identified data from electronic health records concerning induced abortions and women's choice of contraceptive method at the time of an abortion. If there was no contraception chosen, it was recorded as "No chosen method".

Data managers from the participating county health systems retrieved, and de-identified, data from electronic information systems on the number of abortions and the number of LARC insertions within 30 days post-abortion within the geographical area of each hospital, including also youth clinics and primary healthcare for women. Start of LARC was defined as insertion of either sub-dermal implants, Cu-IUDs or LNG-IUS (TQX2O and TLCoo in ICD-10). One team had started to measure insertion of LARC post-abortion manually before the QIC and shared these data with the researchers.

\section{Data Analysis}

\section{Quantitative Data Analysis}

\section{Study I}

We used IBM SPSS statistics version 20, in the statistical analysis (IBM Corp., Armonk, NY, USA). The statistical analyses are summarised in Table I. Repeat abortion during the follow-up period was measured as both a continuous and a categorical variable in the analysis. By using the Chi-squared test, we calculated p-values and presented the outcomes as odds ratios (OR) with 95\% confidence intervals (CI) for the categorical variables: contraceptive method, repeat abortion and abortion method.

We compared the characteristics of the women who selected LARC with women who selected other contraceptives, by using the Student's t-test. 
We adjusted for the possible confounding factors: age, previous pregnancy, delivery and abortions, by using a logistic regression model. By using Kaplan Meier's survival test, we approximated the proportions of women not having a repeat abortion according to their selected contraceptive methods from the time of the index abortion until the first repeat abortion.

\section{Study IV}

We analysed the percentage of women who chose effective contraceptive methods, defined as hormonal contraceptive methods or LARC methods, at the time of an abortion. We also analysed the numbers of women who underwent abortion and the proportion of these who started to use LARC within 30 days post-abortion. To visualise data over time and to distinguish random from special causes of variation, such as shifts in performance, we used Statistical process control charts [151-154]. Control charts display a sequential plot for a measure of interest - e.g. the monthly proportion of women who underwent abortion and who received LARC within 30 days post-abortion - and provide rules for analysing its variation.

\section{Qualitative Data Analysis}

\section{Studies II and III}

Both studies were based on textual descriptions from the interview transcripts. Each transcript was read verbatim several times to get an overview and in each transcript codes or significant statements were noted describing the woman's or the HP's experiences.

In study II, we used interpretive phenomenology, where the focus is on the meaning, structure and essence of lived experiences of a phenomenon for a person. In interpretive phenomenology, the preunderstanding is recognised by the researcher and used in the interpretation of the 
transcripts during the analysis [155]. HK and one of the other researchers are midwives with experiences from providing contraceptive counselling at the time of an abortion. The third researcher (a nurse) has experiences of research in SRH.

The transcripts were analysed according to Moustaka's modification of the Stevick-Colaizzi-Keen method, adding interpretation. Out of each transcript, a textural description was performed, including labelling and arranging each theme. After that, the researchers reflected on the arrangement and variation of the themes and modified the sense of each theme using the researchers' interpretations of the text. The steps above were repeated for each transcript. Finally, textural and structural descriptions were combined from each theme into descriptive general themes. The essence was recognised from the general themes and represented the complete meaning of the experience [155].

In study III, qualitative content analysis was used. This method is described as a systematic process enabling identification, coding and categorisation of a pattern in a text [156]. The transcripts in this study were analysed by using conventional content analysis according to Hsieh and Shannon [157]. Within each transcript, codes were marked to highlight exact words from the transcript that seemed to capture key thoughts. After that, we made notes of our first impressions, views and initial analysis. During this phase, we developed labels for codes which mirrored key thoughts and turned them into the coding scheme. We arranged the codes into clusters, based on how they were connected [157].

In studies II and III, in order to strengthen the validity of the findings, the analyses were performed by three researchers. They analysed the data separately, discussed, and agreed on the definitions of the clusters and the interpretation of the essence. 


\section{Study IV}

Qualitative data (Figure 2) was analysed by qualitative content analysis [156]. HK read through all the collected data and highlighted data describing experiences of the QIC and changes in HPs' counselling and services in clinical practice in the context of an abortion. Data concerning changes in HPs' counselling and clinical practice were categorised in a coding scheme based on the primary drivers - the four areas of evidencebased change ideas - in the Driver diagram [158] (Figure 3). Furthermore, data describing other activities in the QIC, but not matching the drivers, formed a separate category. During analysis, HK divided the categories into subcategories. In order to strengthen the validity of the findings, two additional researchers read through the collected data separately. They discussed with HK until they reached consensus on the analysis. One of the participating HPs in the QIC reviewed the summary of the findings, and co-authored study IV, as a form of participant validation [159]. 


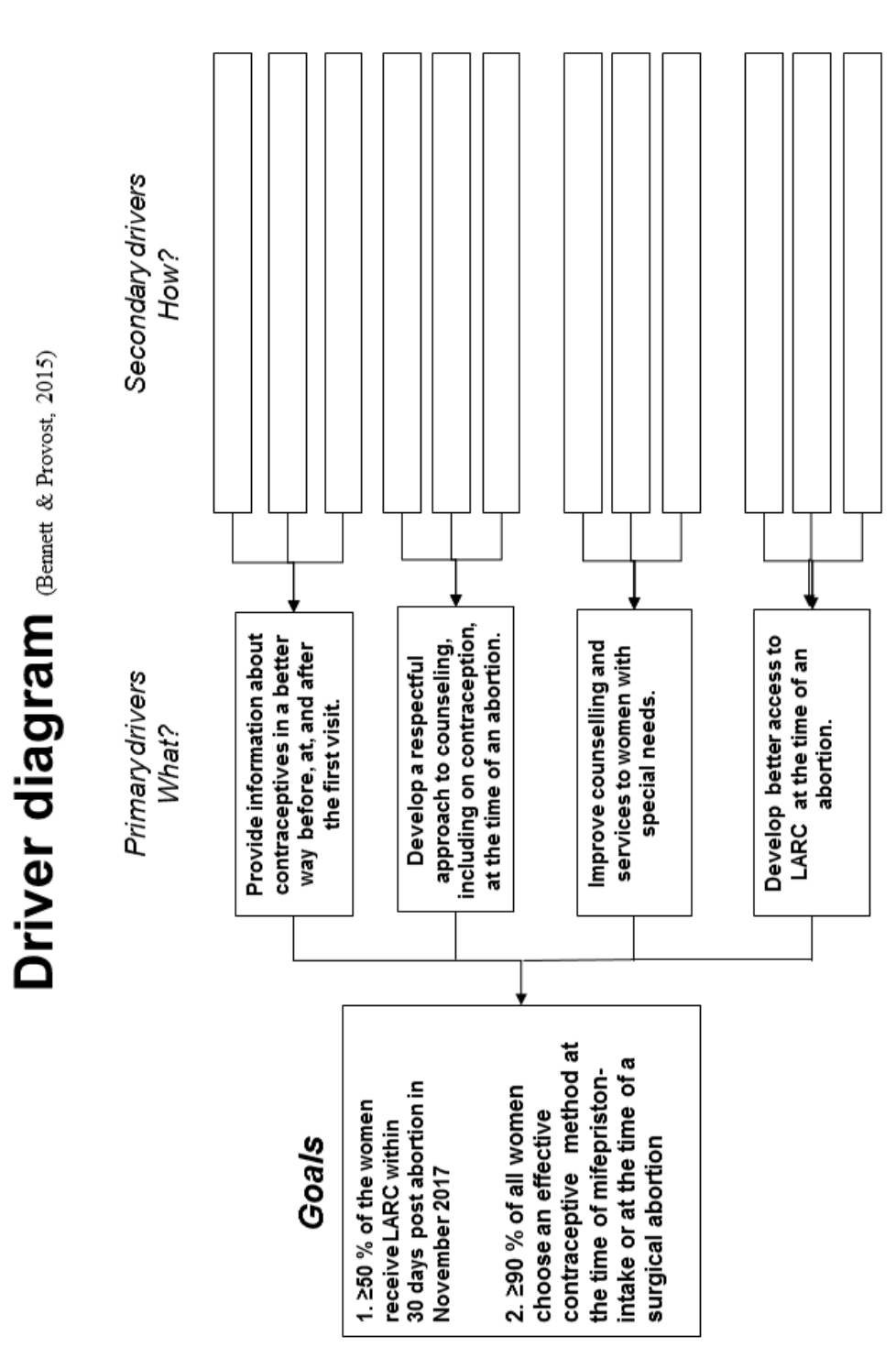

Figure 3. The QIC's Driver diagram with the four primary drivers representing evidence-based ideas for change.

LARC= Long acting reversible contraception. Effective contraception was defined as LARC or hormonal contraceptive methods such as combined oral contraceptive ,progestin only pill, the vaginal conceptive ring, the transdermal contraceptive patch and injection. 


\section{Ethical considerations}

All four studies in the thesis were performed in accordance with the Declaration of Helsinki [160]. The Regional Ethical Board of Linköping approved studies I-IV (reference numbers; \#2013/145-31 (I \& III), \#2016/81-31 (II), \#2016/486-31 (IV). Permissions to review medical records in study I, and to invite HPs/women in studies II-IV, were given by heads of participating departments.

The principle of participants' autonomy was respected throughout the thesis. Participants in studies II-IV received both verbal and written information about the study before they decided to participate. The information underscored that involvement was voluntary and that they could withdraw their participation at any time without explanation or consequences.

Verbal consent was provided in study II, whereas written consent was provided in studies III and IV. In study II, women who showed interest after receiving written information were contacted via e-mail or telephone by HK. They were verbally informed about the study. If they accepted an interview four to six weeks after the abortion, this was considered to be informed consent.

The principle of not causing harm was considered during the research process. In study I, it was considered not possible to obtain informed consent from the women, who experienced an abortion in 2009. A secure process to de-identify these women's medical records was undertaken. Local administrators at each hospital de-identified and coded all the medical records before the researchers reviewed them. None of the researchers had access to the coding list. To protect sensitive information regarding abortion, all medical records or data from digital records were 
de-identified in studies I and IV. Medical records were kept in secure, locked locations and only one secretary in each department had access to the coding list in study I. All transcripts from the interviews in studies II and III were de-identified and coded. They were kept in secure locations and only the researchers had access to them. Participating women in study IV shared their views in anonymised form; only HK had access to their mail-addresses and phone numbers.

The risk of burdensome experiences was taken into account. In studies II and IV, women were contacted and shared their experiences of contraceptive counselling in connection with the abortion visit. The women's attitudes towards contraceptive use or choices were not questioned. If women indicated that they needed additional counselling regarding contraceptive choices or the abortion experience, they were guided to an HP or a social worker. In study III, HPs were interviewed regarding their experiences of providing contraceptive counselling at the time of an abortion. Their recommendations or approaches to contraceptive advice were not questioned.

The principle of beneficence was considered when planning and conducting the research. Doing good implies that the research is likely to yield benefits for the person or groups to whom it is addressed. This thesis may provide an increased understanding of different aspects of contraceptive methods and contraceptive counselling in clinical practice. This understanding can help HPs in abortion care to counsel and support women to prevent repeat UPs. 


\section{RESULTS}

The results of the thesis are organised into the following three themes:

I) Contraceptive counselling - a complex meeting at the time of an abortion, II) Women's choices, need for guidance and access to contraceptive methods, and III) To collaboratively design and seek to improve counselling and services in abortion care.

\section{Contraceptive counselling - a complex meeting at the time of an abortion}

Both women and HPs often experienced contraceptive counselling at the time of an abortion as a complex meeting, illustrated in Figure 4 (studies II-III). Women described the complexity of being caught in the unwanted emotionally charged situation of being unintentionally pregnant as like a state of limbo, where they were also sceptical about contraception (study II). The time of being unintentionally pregnant was illustrated as hell, chaos or darkness, from within which women often reported limited receptivity to information and counselling regarding contraceptive methods. Women also described a vulnerable position where it was easy to be condemned as having failed in contraceptive use (study II). A risk of condemning was also reported by HPs, as well as consultations involving intimate issues regarding women's sexual relationships (study III).

The need for respectful counselling was central among women's requirements as they described feelings of guilt and shame. They described a respectful HP as someone who was neutral, not judgemental, who listened, was empathetic and who clarified the woman's right to decide whether to terminate the pregnancy or not (study II). 


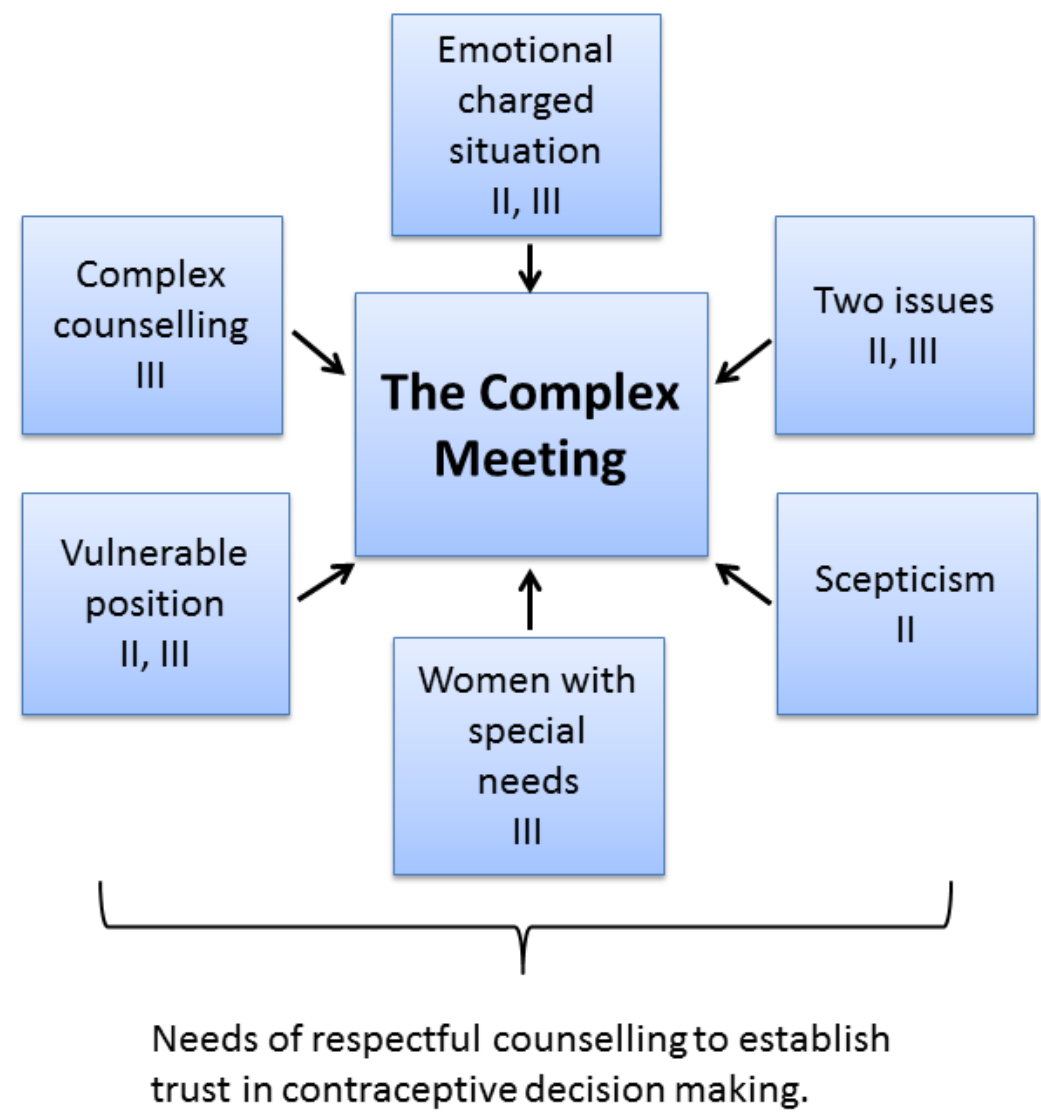

Figure 4. The complex meeting: contraceptive counselling at the time of an abortion.

Results from the perspectives of women and health professionals, based on the findings from studies II and III.

According to both women's and HPs' experiences, forming a partnership and establishing trust are central in contraceptive counselling at the time of an abortion, mirroring PCC (studies II and III).

When you have a conversation about terminating a pregnancy you need an empathic listener. I did not experience understanding and did not dare to talk about difficulties and fear regarding using hormones. I felt bad; I had already failed in using contraceptives. Woman code 8 , study II. 
It is important that the woman feels safe. You need some kind of intuition when you talk about contraceptives in the context of a termination.

HP code 9, study III

Women who experienced respect reported that they often established trust in the HP, which enabled contraceptive decision-making. They also stated that they were capable of having a conversation about contraception and open to receiving help in decision-making, even if the situation was emotional charged (study II).

HPs described the consultation at the time of an abortion as usually a complex meeting, dealing with two issues - abortion and contraceptive counselling (study III). On the other hand, women stated that they were primarily focused on one issue - the abortion (study II). HPs described challenges in establishing trust when meeting women with special needs on top of these two issues. Women with special needs were described as women with linguistic barriers, women with mental health problems and women who declined offers of contraceptives and who had experienced repeat abortions. HPs reported that there were women who had complicated life situations that made them extra vulnerable with increased needs for trust and individualised counselling. HPs often had difficulties in understanding these women's needs (study III).

It was common in study II for women to report difficulties in finding a contraceptive method that worked for them. The women stated a general scepticism towards contraceptives, which was seldom discussed in the counselling at the time of an abortion. Women who reported being questioned as unintentionally pregnant did not dare to express their scepticism about contraception.

Scepticism was described as fear of using hormones, fear of possible side effects and negative experiences of previous contraceptive use. Women 
described how respectful counselling and meeting a skilled HP influenced their choice of contraceptives. Women who were initially sceptical about contraceptives described how they changed their minds and decided to use contraceptives, even in an emotionally charged situation (study II).

\section{Women's choices, need for guidance and access to contraceptive methods}

Women's choice of contraceptive methods at the time of an abortion $(n=987)$ and the relation between contraceptive choice and the odds of repeat abortions were stressed in study I. In study III, oral contraceptives (OC) were often recommended as the first choice at the time of an abortion, recommended by HPs as the most satisfying method. In study I, consequently $46 \%$ chose $\mathrm{OC}$ at the time of an abortion, whereas $34 \%$ selected LARC (Figure 5). OC included combined oral contraceptives (COC) and Progestin only pill.

LARC was chosen more often by women with a previous pregnancy, childbirth or abortions (study I). This was also reflected in interviews with HPs, where Cu-IUD/LNG-IUS were seldom recommended to nulliparous women, related to HPs' fear of their causing infertility (study III). 


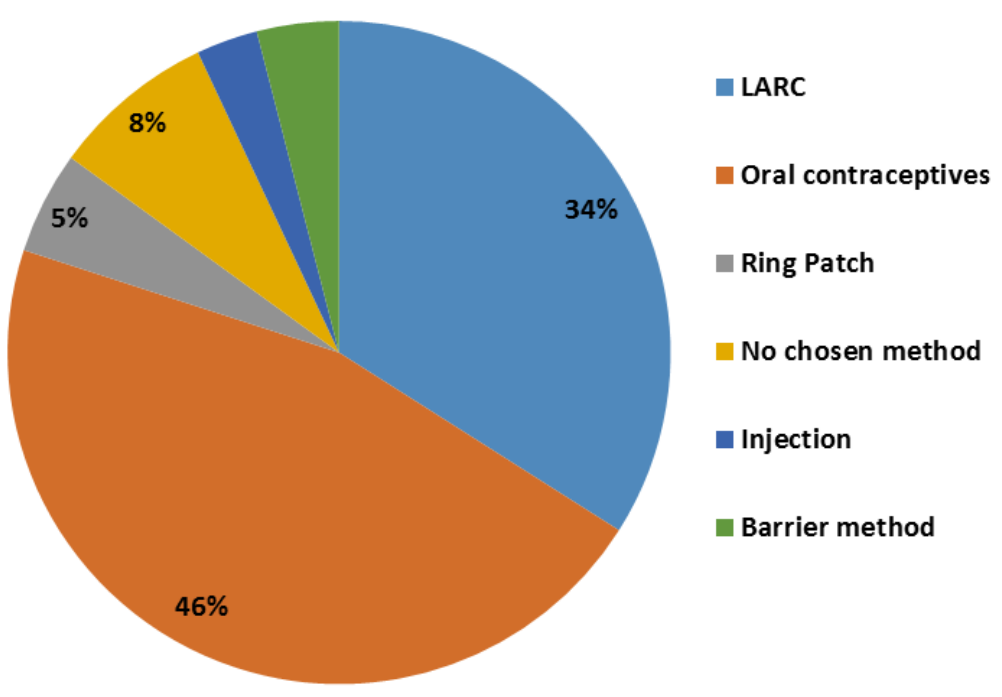

Figure 5. Women's ( $n=987$ ) choice of contraceptive method at the time of the index abortion 2009.

LARC $=$ Long acting reversible contraception; Oral contraceptives $=$ Combined oral contraceptives, Progestin only pill; No chosen method = No choice of contraceptive method in the record.

In study I, $24 \%$ of the women experienced one or more repeat abortions within three to four years. Of these, $5 \%$ underwent two or more abortions. The median time was 17 months until the first repeat abortion among the 239 women. Choice of LARC was associated with fewer repeat abortions within three to four years compared with other contraceptive methods, as well as OC post-abortion (Table 4). Choice of subdermal implant was as effective as IUDs/LNG-IUS in preventing repeat abortions (study I). 
Table 4. Choice of contraceptive method and odds of repeat abortion(s)

\begin{tabular}{|l|l|l|l|}
\hline $\begin{array}{l}\text { Contraceptive } \\
\text { methods }\end{array}$ & Women & $\begin{array}{l}\text { Odds of repeat } \\
\text { abortion(s) }^{\mathrm{b}}\end{array}$ & $\begin{array}{l}\text { Adjustmentsfor } \\
\text { potential confounding }^{\text {factors }^{c}}\end{array}$ \\
\hline Comparing groups & $(\mathrm{n})$ & $(\mathrm{OR} / \mathrm{Cl})$ & $(\mathrm{OR} / \mathrm{Cl})$ \\
\hline LARC/ no LARC & 987 & $0.33(0.23-0.47)$ & $0.29(0.19-0.44)$ \\
\hline LARC/OC $^{\mathrm{a}}$ & 785 & $0.36(0.24-0.52)$ & $0.26(0.15-0.42)$ \\
\hline
\end{tabular}

a $\mathrm{OC}=$ Oral contraceptives, which includes combined oral contraceptives, and progestin-only pills. ${ }^{\mathrm{b}}$ The Chi-square test was used to calculate p-values and presented as Odds Ratios (OR) and 95\% confidence intervals (CI).c A logistic regression model was used to adjust for age, previous pregnancies, childbirths and abortions.

In study I, during the follow up time, $90 \%$ of the women who chose LARC avoided a repeat abortion, whereas $75 \%$ of the women who selected OC did so. Women who, according to the medical records chose no method, had similar proportions of repeat abortions as women who chose OC, Figure 6 (study I). The likelihood of a repeat abortion during the followup time was significantly lower among women choosing LARC compared to all other choices $(\mathrm{p}<0.001)$, Figure 6. 


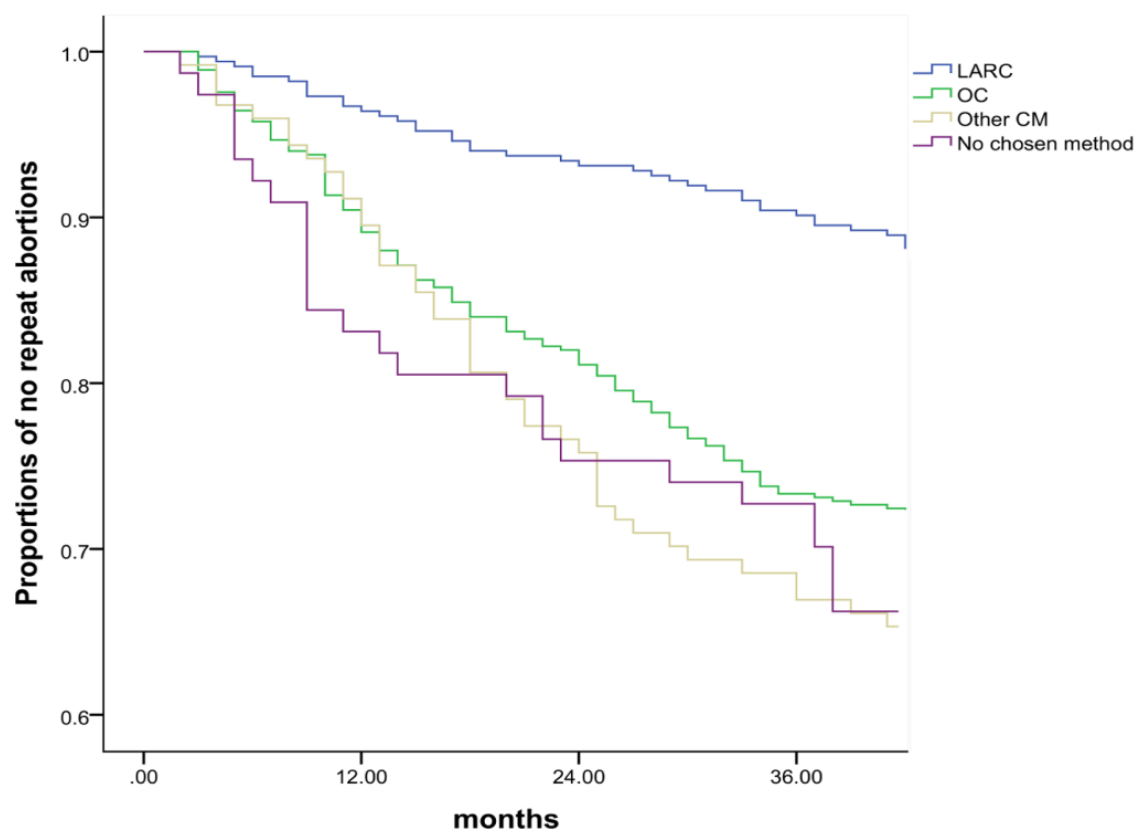

Figure 6: Probability of not having a repeat abortion according to chosen contraceptive method $(n=985)$.

Calculated with Kaplan Meier's survival test from the date of the index abortion until the first repeat abortion. LARC $=$ Long acting reversible contraception, OC (Oral contraceptives) $=$ Combined oral contraceptives and Progestin only pill. Other CM (contraceptive methods) = Injections, the vaginal conceptive ring, the transdermal contraceptive patch, Barrier method. No chosen methods $=$ No choice of contraceptive method in the record.

In study II, women reported receiving insufficient information and guidance regarding the side effects of contraception alternatives, indicating a need for enhanced SDM. It was common for women to express a need for more information regarding possibly side effects in different contraceptive methods (study II). Women also reported that fear of side effects were seldom discussed at the time of an abortion. Women who reported unmet needs for information and guidance stated that HPs lacked confidence and competence regarding contraceptive counselling (study II). 
It was common in study III for HPs to report limited theoretical and practical skills in contraceptive methods. They also stated inadequate confidence about counselling women who were sceptical about contraceptives (study III). Women who reported meeting a skilled HP described counselling in which the HP could answer her questions about side effects and meet her fears regarding hormones (study II). A skilled HP could also guide the woman in her contraceptive decision -making according to her previous experiences and individual needs. Women who were content with counselling were often introduced to a visual aid ranking the effectiveness of different contraceptive methods. This aid facilitated the woman's choice of contraception (study II).

Insufficient counselling and services in line with women's individual needs was reflected in interviews with women and HPs, in studies II and III. The first visit was often considered to be an emotionally charged situation (studies II and III). As a consequence, women wanted a followup visit to discuss contraception (study II). On the other hand, women also stated that it was important to receive contraceptive advice during initial abortion counselling as they might not priorities making an additional appointment for contraceptive counselling. Women wished for a prolonged and flexible time regarding contraceptive decision-making and asked for additional time if needed without feeling stressed. Those who stated mental health problems described struggles with trying to call an unknown midwife after the abortion to make additional appointments (study II).

Both women and HPs stated that women had a need for coordinated access to LARC within counselling (studies II and III). Women who chose LARC at the time of an abortion reported barriers to getting an IUD/LNG-IUS inserted (study II). They described difficulties in receiving 
appointments for insertion, some forgot to call, and some had problems in reaching midwives in general healthcare by telephone post-abortion. There were also women who expressed worries about a painful insertion. Some women were still waiting for IUD/LNG-IUS insertion four to six weeks post-abortion (study II). In some abortion services, HPs were able to offer appointments for IUD/LNG-IUS insertion; others referred women to book appointments by themselves within general healthcare. HPs stated that it was common for the women to be unable to get the appointments they needed (study III).

It was important for me to receive an appointment for IUD insertion. They understood my needs even better than myself. I am working full time, have small children and there is not much space for booking appointments.

Woman, code 6, study II.

\section{To collaboratively design and seek to improve counselling and services in abortion care}

Study IV describes a QIC and evaluates the teams' efforts to improve counselling and services with user involvement. The QIC drew on the findings of studies I-III, revealing opportunities to redesign and improve contraceptive counselling and services at the time of an abortion. Performed as part of regular health services, the QIC involved multiprofessional teams from three Departments of Obstetrics and Gynaecology (Appendix 1). The teams jointly agreed on goals (Figure 3), informed by previous findings on women's choice of contraceptive methods (study I) and local statistics from one department. They discussed the four evidence-based primary drivers derived from studies I-III and the literature in the field. The drivers concerned ways to facilitate women's choice of contraceptive methods and start of effective 
contraception, including how to support women with special needs, i.e. women with language barriers, women with mental health problems, and women who decline offers of contraceptives and women who have experienced repeat abortions. The HPs in the QIC considered women's experiences regarding contraceptive counselling (study II), the other teams' experiences of the unfolding improvement efforts and the two women's views on the teams' ideas. The QIC teams also participated in analysing quantitative data from their departments regarding women's choice of contraceptive methods and start of LARC, during the QIC.

The teams were introduced to two decision aids regarding contraceptive methods' effectiveness and side effects (Appendices $2 \& 3$ ). These aids aimed to facilitate contraceptive counselling and help HPs to meet women's needs for information and guidance in SDM. The two women with user experience in the QIC described the two aids as helpful for choosing a contraceptive method at the time of an abortion. The second decision aid (Appendix 3) was translated into Arabic, as requested by the teams.

The professionals interacted in two sessions regarding how to develop respectful counselling and manage challenging consultations involving the discussion of contraceptive use by utilising the approaches of MI and SDM (Appendix 1). The sessions were inspired by findings from studies II and III and by the principles of PCC, SDM and MI. Two researchers and a participating social worker trained in MI, led the sessions according to needs stated by the HPs. All teams planned improvement efforts according to the four primary drivers (Figure 3). They reported varying degrees of testing and maintaining changes at their departments during the QIC (Appendix 4). 


\section{To develop contraceptive counselling}

Participating HPs (midwives and gynaecologists) reported that they focused more than before on contraceptive counselling after introducing changes in clinical practice (Appendix 4). They also reported that the sessions and the two women's views in the QIC had inspired them to involve women more than before in contraceptive decision-making. Participating HPs stated that they tried harder than before to understand women who declined offers of contraception. They also reported increased knowledge about contraceptive methods and confidence in counselling after the lectures and discussions at the LSs.

\section{To develop access to LARC}

The HPs arranged and added more appointments to IUD/LNG-IUSinsertion to facilitate timely and coordinated access, spurred on by the women's suggestions in the QIC (Appendix 4). Coordinated access to contraceptive services is in line with PCC and the prevention of repeat UPs. However, all the teams reported discovering obstacles to developing better access to LARC. Local leadership support varied as well as the opportunity to reach colleagues with information regarding the improvement efforts. Teams A and B found it difficult to improve access to LARC initially, without performance data feedback at LS1-LS2 regarding the start of LARC after an abortion. Team C, on the other hand, was helped by the manual data collection and feedback system that had been initiated before the QIC. All teams updated their data classification regarding the start of LARC at the time of an abortion, in their electronic clinical information system.

\section{Progress towards QIC goals}

Almost $90 \%$ of the women $(n=594)$ undergoing abortion at the three departments during the QIC selected an effective contraceptive method (hormonal contraception or LARC); 60\% of these women chose LARC, 
during the six months of the QIC. However, none of the teams reached goal 1 ( $\geq 50 \%$ of women start LARC within 30 days post-abortion). The control charts showed no signals of statistically significant change in the proportion of women initiating LARC within 30 days during the QIC compared to the pre-QIC baseline (Figure 7). In Team C's department, $40 \%$ the women started to use LARC within 30 days post-abortion. The department offered appointments for the insertion of IUD/IUS and subdermal implants within 10 days post-abortion.

\section{Participants' experiences of the QIC}

At the concluding LS, participants reported that the QIC had inspired them to continue to improve contraceptive counselling and services at the time of an abortion. They valued interacting with other teams, including different professionals, and sharing experiences. Several midwives reported that, due to their participation in the QIC, they had resumed inserting IUDs, after not having done so for many years. All the teams described spin-off changes during the QIC in other parts of their services (Appendix 4). 


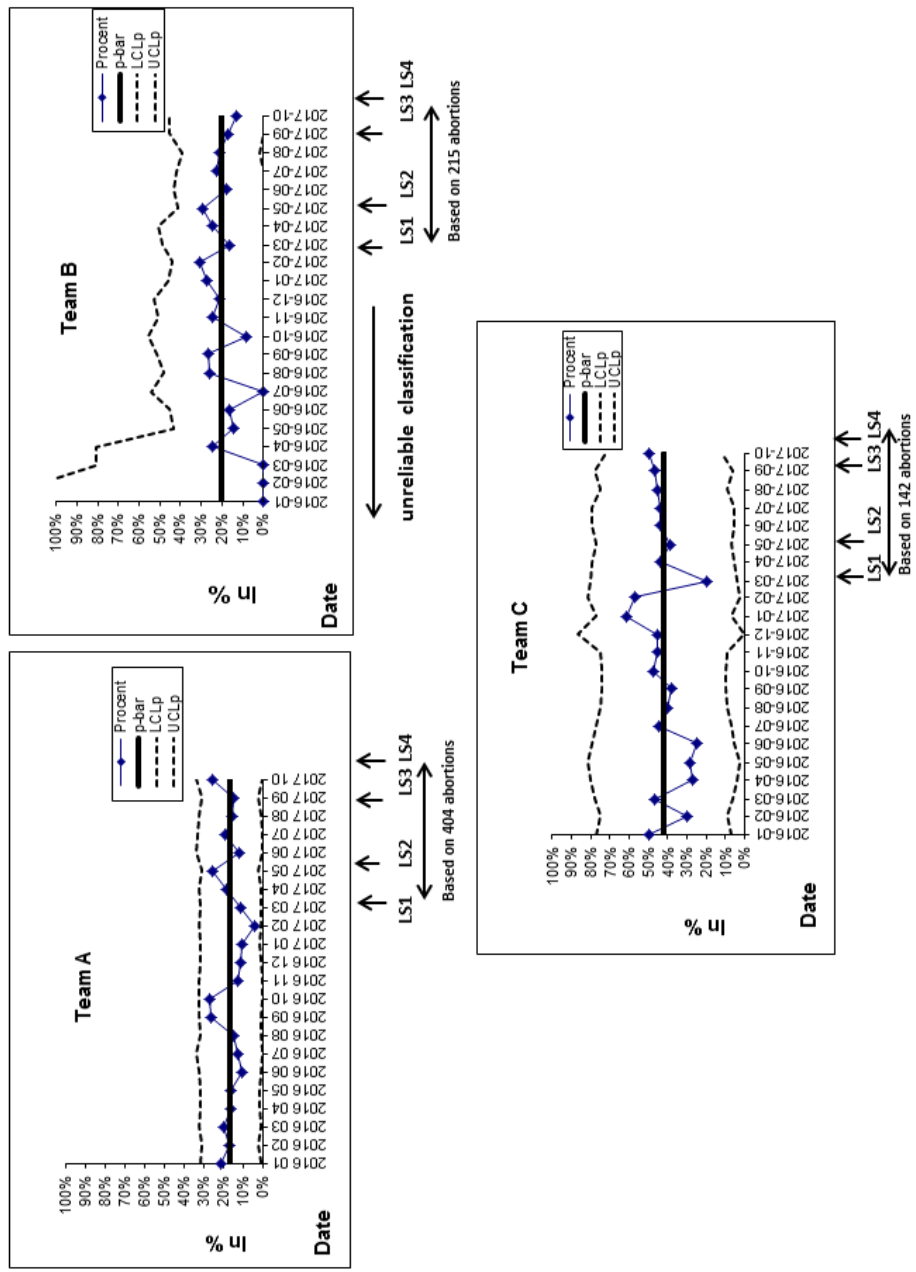

Figure 7; P-charts showing the monthly proportion of women who initiated LARC within $\mathbf{3 0}$ days post-abortion in the departments of Teams $A, B$ and $C$.

The start of LARC is defined as the insertion of LARC in the medical records according to classifications. Data for Teams A and B is based on digital data from existing information systems regarding the insertion of LARC in the context of abortion. For Team C, data is based on manual measurements. LARC = Long acting reversible contraception. LARC is defined as subdermal implants, Levonorgestrel-intrauterine systems or Copper intrauterine devices. LS = Learning session. $\mathrm{P}-\mathrm{bar}=$ the average of all observations. LCLp and UCLp $=$ Lower and Upper Control Limits for proportions (reflecting the range of variation and number of patients per month). 
Results 


\section{DISCUSSION}

\section{General findings}

The complex meeting and the importance of respectful counselling at the time of an abortion (studies II and III) highlight the need for PCC [132, 138] to improve women's SRHR. Few studies have reported how respectful counselling in the often emotionally charged context of an abortion influences -sceptical - women to make a choice of contraceptive method post-abortion [14, 19, 64]. Scepticism about contraception, as found in study II, may partly explain why some women discontinue, or never initiate, use of contraceptives post-abortion and are at higher risk of a repeat UP. These findings (study II) differ from quantitative studies reporting higher motivation for contraceptive use post-abortion $[2,3,86$, $161]$.

Respect seems to be extremely important in the context of an abortion compared to contraceptive counselling in general, as there are risks of condemnation and pressure to choose a certain contraceptive method after an UP (studies II and III). These risks were also identified in previous research [14, 64]. Risks of infringement regarding sexually intimate topics in the context of abortion (studies II and III) demonstrate the value of health-promoting activities that strengthen the partnership and women's SRHR. Especially as, HPs in study III described the complexity of establishing trust when counselling women with special needs on top of abortion and contraceptive counselling. Difficulties in establishing trust can explain why some women distrust HPs in contraceptive decision-making and choose not to use an effective contraceptive method. 
The complex meeting at the time of an abortion involved women's difficulties in finding a contraceptive method that worked for them (study II), which has also been found in other interview studies [19, 54]. According to our findings, women with linguistic barriers, women with mental health problems, women who have experiences of repeat abortions and women who decline offers of contraception seem to have special needs for individualised counselling and coordinated care (study III). This is in line with previous studies $[54,162,163]$.

Women's views (study II) indicated that there is insufficient guidance or information about the choice of contraceptive methods; there is room for improvement in counselling, in line with other studies [19, 54]. Furthermore, HPs sometimes described limitations in their knowledge of contraceptive methods and their confidence in counselling (study III). In the context of an often-complex consultation, this may explain why some HPs struggle in counselling women who are sceptical of contraceptives (studies II and III). Inadequate skills and lack of confidence among HPs can also explain why some women do not receive information and guidance in contraceptive decision-making at the time of an abortion (study III), a problem also reported in previous studies [14, 164, 165]. HPs' individual views and preferences regarding contraceptive methods (study III) may also influence women's choices and scepticism [166]. Contraceptive counselling based on HPs' personal preferences (study III) is not in line with PCC, within which evidence-based knowledge should be provided to prevent repeat UPs and improve SRHR [133].

Women's reported needs for guidance and access in their choice of contraceptive method (study II) indicate that there is room to strengthen support to enable women to prevent repeat UPs. The choice of LARC was associated with fewer repeat abortions (study I), pointing in the same direction as previous studies $[41,104,105]$. The choice of OC dominated 
in women's contraceptive choices (study I), as in other studies at the time of an abortion [2, 3]. It was often also reported as the first recommendation made to nulliparous women by HPs at the time of an abortion (study III). Both HPs and women seem to overestimate the effectiveness of OC at the time of an abortion (studies II and III), in line with previous research [3, 97]. This overestimation may partly explain why some women experience repeat abortions, as illustrated in study I. The results reflect the effectiveness regarding contraceptive methods under real-world conditions (study I). This knowledge is important to highlight when providing contraceptive counselling aiming to support women's ability to control their reproduction. There is a difference between efficacy in strictly controlled studies and effectiveness in real-life clinical practice [167]. About 60\% of the COC users report irregular use, which drastically reduces the effectiveness [168]. In contrast, LARC involves few user failures [101] and prevents repeat abortions more effectively, as found in study I.

LARC is, however, not the best option for all women, even if more women continue to use LARC within a year compared with OC [102]. There is no single method that suits every woman. Women have individual needs and may prefer different contraceptive options (study II) at different stages of their lives [65]. COC can be a good option for some women. Long-cycle use of COC after abortion could be an alternative [100]. However, less is known regarding long-cycle use of COC post-abortion and its effectiveness in preventing repeat UPs and abortions [100].

To collaboratively seek to improve counselling and services, aiming to facilitate women's choice of contraceptive methods and use of LARC (study IV), could inadvertently risk putting pressure on women to choose a specific method. This could "backfire" and lead women to distrust HPs' contraceptive counselling $[64,92]$. HPs might put more effort into 
increasing the choice of a contraceptive method in order to achieve performance goals rather than to meet women's individual needs. This would contradict the principles of PCC, where partnership is central. On the other hand, health-promoting activities are required to strengthen women's SRHR and to increase their knowledge about contraceptive methods $[5,6]$. It also involves improving the quality of contraceptive services, including better coordinated access to contraceptive methods $[126,169]$. Limitations in information, guidance and access to effective contraceptive methods would decrease women's ability to achieve reproductive autonomy and control.

To guide a woman towards what seems best, based on her individual needs and according to evidence-based knowledge, is in line with PCC [143, 144], but can be demanding for HPs when women decline offers of contraception [14]. HPs stated ethical dilemmas if not understanding women who declined offers of contraception when they were trying to support them to avoid a subsequent UP (study III). Women and HPs might have different intentions regarding the prevention of repeat UPs. HPs have a professional role to convey knowledge about contraceptive methods and to prevent repeat UPs, according to the goals of SRHR. However, the experience of demanding consultations indicates a need to develop the approaches of PCC in counselling in order to understand women's needs.

Some women might decline offers of contraception due to experiences of negative side effects in contraceptive use and might experience that contraception limits their reproductive autonomy instead of increasing reproductive control. They might find abortion to be a solution to repeat unintended pregnancies, instead of using contraception. 
Use of approaches such as SDM and MI in contraceptive counselling probably provides more room for women and HPs when interacting in decision-making. These approaches may strengthen the partnership, preventing misunderstandings as well as arguing for change [140, 144] when women decline offers of contraception. On the other hand, there might be conflicts between these approaches. MI could be interpreted as persuading a woman to choose what the HP wants, whereas SDM could be understood as free selection of contraceptive choices. The equal partnership in person-centred care could be also be misunderstood and interpreted as equal experts. A woman is expert regarding her contraceptive experiences, but an HP is expected to be expert in contraceptive methods, to provide evidence-based information and to have the competence to guide each woman in her individual situation.

The reproductive life plan (RLP) $[65,170]$ is a health-promoting tool that invites a broader conversation about women's reproductive lives and wishes, including when women decline offers of contraception. This tool seems to support women in their plans for future pregnancies and could be a useful tool in counselling. There is still limited knowledge regarding the feasibility and benefits of using RLP at the time of an abortion. According to study IV, a QIC based on user involvement and PCC may strengthen HPs' competence in supporting women to find a suitable contraceptive method and practical skills in providing LARC. They also described new ways of connecting with women after participating in the QIC (Study IV). Previous research has observed strengthened benefits of using QICs when improving contraceptive counselling and services based on both PCC and RLP [126]. To our knowledge, there are few QICs based on user involvement seeking to improve contraceptive counselling and services performed in the context of an abortion. 
Women's need for coordinated access to effective contraceptive methods seems to be crucial at the time of an abortion (studies I and II) when preventing repeat UPs. A previous study demonstrates the benefits of coordinated access to LARC post-abortion in the prevention of repeat UPs [104]. Coordinated access to care is a central part of PCC [131, 138]. However, none of the teams in the QIC reached their goals in meeting women's need for access to LARC within 30 days, even though the majority of women chose LARC (study IV). As in previous studies, some women might fail to schedule follow-up visits to initiate LARC [41, 85] and might not identify the risk of UP if using no contraceptive [69, 171]. This might partly explain why the teams did not reach their goal in meeting women's need for access to LARC (study IV).

While few previous studies have evaluated access to LARC post-abortion, study IV revealed practical barriers to providing access in clinical practice. These practical barriers, and the teams' difficulties in overcoming them, indicate that coordinated access to LARC needs more attention in abortion care. The teams experienced differing support from their local leadership (study IV). These factors are very likely to affect women's access to LARC [172] and might explain why some women experience repeat UPs and abortions. Moreover, even if choice of LARC is the most effective method for preventing repeat abortions, as found in study I, coordinated access to LARC is still not fully achieved in clinical practice, according to study IV.

This thesis highlights the importance of support from managers, when seeking to improve counselling and prevent repeat UPs in abortion services (study IV). Sannisto et al. [172] found that the quality of contraceptive services was associated with the quality of leadership [172], mirroring implementation research more broadly [173]. PCC needs to be applied at all levels of healthcare organisation, from the head of 
department to the team, to facilitate PCC in the meetings between women and HPs, as well as coordinated access to care [131, 138], including at the time of an abortion.

Another important contribution of this thesis is that the QIC helped the team members to understand what needs to be taken into account in different contexts in order to improve performance, and which support is necessary to change systems $[150,174]$. Feedback performance data from digital systems was difficult to access in the QIC, despite considerable efforts and the documented importance of having performance data when improving healthcare [121]. Digital performance data feedback was far away from HPs (study III), except when a team measured such data manually (study IV). This reflects the difficulties in evaluating contraceptive counselling in abortion services and highlights an opportunity to develop digital performance data to facilitate the evaluation of performance in abortion services when preventing repeat abortions.

This thesis demonstrates women's needs for respectful counselling, guidance and coordinated access to contraception post-abortion. Furthermore, it indicates the feasibility of collaborative efforts to improve counselling and services with user involvement. This thesis has also generated health-promoting actions that were directly applied in clinical practice to support women's reproductive control and prevent repeat UPs (studies I-IV).

\section{Strengths and limitations}

This thesis provides a wide perspective on contraceptive choices and counselling in abortion care, including both quantitative and qualitative methods, multiple data sources and four independent data collections. The studies illuminated both women's and HPs' views. 
A strength of this thesis is that the studies were performed in two counties with sociodemographic diversity and different rates of repeat abortions. All the studies involved differently sized hospitals; one university hospital, two central hospitals and two district hospitals. In studies I-IV, abortion care varied as to whether specially trained midwives or only gynaecologists provided abortion counselling and contraceptive services. There was also a wide range of professional experience among HPs (study III) and in the multi-professional teams (study IV). Furthermore, there was a diversity of ages (studies I-III), women's reproductive history (studies I-II) and participants' educational level (studies II and IV).

In study $I$, the sample size $(n=987)$ in the medical record review was in line with the power calculation $(n=750)$. The majority of abortion services in Sweden are provided by public healthcare; therefore, the majority of women who underwent abortion in the areas of the hospitals were included in studies I and IV. However, it was not possible to evaluate women's actual use of contraception in studies I and IV, except LARC in Study IV. Women's actual use of LARC was evaluated within 30 days post-abortion, according to the classification in digital data systems or manual data collection from records (study IV).

Both medical records (studies I and IV) and digital data systems (study IV) exhibited shortcomings with regard to missing data on abortion and contraceptive classifications. This should be considered when interpreting the results of studies I and IV. It is possible that some women discontinued or did not use the method they had selected, according to the records (studies I and IV). In study I, not starting use of LARC or discontinuing use are likely to be the major reasons for pregnancy and repeat abortion among the women who selected LARC. 
We were not able to collect data regarding sociodemographic factors, relationship status, sexual violence or ethnicity (study I). This would have been preferable as risk of repeat abortion is associated with socioeconomic challenges such as foreign origin and sexual violence [9, $38,54,162]$. Women with complicated life situations and relational conflicts may face greater difficulties and needs for support in contraceptive decision-making at the time of an abortion (studies II and III). Furthermore, only Swedish-speaking women and women aged over 20 were included in study II. This might limit the understanding regarding adolescent's experiences of contraceptive counselling given at the same time as abortion counselling. Previous Swedish research regarding sociodemographic status at the time of abortion is scanty [13], since no abortion register exists.

There are several other limitations to consider in this thesis. First, we did not include the male perspective on contraceptive counselling. In this thesis, we have chosen the perspective of women in the context of an abortion. However, it is important to involve both women and men in health-promoting activities regarding SRHR $[5,6]$.

Second, there were few midwives $(n=6)$ and few men among the participants in study III. This might reflect the numbers of midwives and men among HPs in Swedish abortion care.

Third, we did not evaluate the impact of PCC regarding women's experiences of contraceptive counselling or satisfaction in the choice of contraceptive methods (study IV). On the other hand, improved contraceptive counselling inspired by PCC and user involvement would probably identify women's resources and needs in a better way [127, 140] as HPs reported developed conversations and connections with women during the QIC (study IV). 
Fourth, study IV did not cover the effects of the QIC in the three departments among HPs who were not on the QIC teams. Further, only three teams participated in study IV, which could been seen as a small number [122, 124], as well as only two women providing user perspectives in the QIC. On the other hand, the teams' departments served 761 women experiencing an abortion during the QIC. The teams in study IV took also part in the findings in study II, which included 13 women's lived experiences of counselling in the context of an abortion.

\section{Validity and reliability}

The quality of research can be assessed by considering different aspects of the data collection and analysis. Validity and reliability are concepts used in both quantitative and qualitative studies [150, 175, 176], whereas trustworthiness has been used predominantly in qualitative studies. However, strategies for verifying trustworthiness have been criticised as they only evaluate and do not confirm rigour, as they are applied after the research has been completed. It is therefore recommended to use reliability and validity for ensuring rigour as these terminologies are central in both scientific paradigms [175].

When quantitative studies are performed, as in study I, there is often a desire to produce results that may be generalised to the wider population from which the sample was drawn. In study I, there are a number of limitations and cautions to consider when it comes to the external validity of the results. This study included women who experienced abortion in the year 2009; a number of them were unavailable for follow-up as they had moved out of the catchment areas. The results might also be considered as old (2009). However, the rate of repeat abortion amongst these women, $38 \%$, was in line with national abortion statistics in Sweden 
for 2009 [148], and the main results pointed in the same direction as previous studies in the field $[41,104]$.

Construct validity was considered when pilot testing the standardised form used for the medical record review (study I). Furthermore, both construct validity and reliability were considered when creating a feedback system in study IV. To ensure the correct operational measures and that the data collection could be repeated with the same results, manual and digital data were analysed and compared together with the QIC teams (study IV) [150].

In study IV, both quantitative and qualitative data were collected from multiple sources, such as digital records, field notes, project documentation, a group session and a survey. Case study design has been criticised as generating large amounts of quantitative of data, while the analysis has been criticised as unsystematic and complex [174]. On the other hand, multiple data sources in a case study enable triangulation to strengthen the construct and internal validity [150, 174]. Furthermore, data was collected by three researchers and an Improvement Advisor (study IV). The teams participated in the analysis of quantitative data during the LS ( study IV), as a form of interactive validation [159]. One of the team members participated as a co-author in the manuscript and was active in the analysis of the data (study IV), a form of participant validation [159]. This increases the internal validity as learning between the researchers and the participants in a QIC can create reflexivity [159].

The findings from studies II and III, using qualitative methods, aimed to increase an understanding of a phenomenon in a special context [156]. Reliability and validity refer to the amount of truth in the findings [176]. The reliability and construct validity were also considered when creating and pilot testing the interview guide (study III) as well as the open-ended 
request (study II) before conducting the interviews. The interviews in this thesis created rich and explanatory material, which enabled both depth and width in the analysis (studies II and III).

In qualitative studies, five verification strategies can be used to ensure validity and reliability [175]. These terms are: 1) methodological coherence; ensuring that the research inquiry matches the method and in turn matches the analysis. 2) Appropriate sample and adequate participants [175]. This thesis included women with lived experiences of contraceptive counselling and HPs' experiences of providing counselling in the context of an abortion. The numbers of included participants in studies II-III ( $\mathrm{n}=13$ and 21) was in line with recommendations for the chosen methods [177]. 3) Collecting and analysing data concurrently. 4) Thinking theoretically: developing new ideas but also rechecking the ideas to confirm that they are grounded in the data. This was taken into account when presenting quotes linked to themes and clusters in studies II and III. 5) Theory development; moving from a micro level to a macro level in theoretical understanding [175].

To strengthen the reliability and validity, the researcher needs to take her pre-understanding into account [176]. Three researchers had different pre-understandings of the issues in studies II and III. The preunderstanding of the author (HK) was used in the final steps of the analysis in study II and was expected to deepen the themes and essence, whereas this was not the case in study III. Interpretive phenomenology goes beyond content analysis to develop a nuanced understanding of the lived experience $[155,157]$. To have knowledge about the research field and experience from the context is a benefit, as long as it does not affect the participants or the interpretation of the findings [176]. In the analysis of studies II and III, three researchers analysed the data separately, then later on they discussed and agreed on the findings. 


\section{Clinical implications}

The findings of this thesis can inform efforts to improve contraceptive counselling at the time of an abortion in other abortion services in similar contexts. Training in respectful counselling, such as the approaches of person-centred care and MI, ought to help HPs in developing trusting relationships with women seeking abortion.

Guidance in contraceptive decision-making needs to be improved, by the use of decision aids regarding effectiveness and side effects at the time of an abortion (Appendices 1 \& 2). Access to LARC post-abortion needs further attention as it is still not sufficient in clinical practice. Coordinated and early access to LARC should be provided at the time of an abortion, for women who choose LARC, to support their reproductive control and prevent repeat abortion. QICs and user involvement based on PCC can be used to stimulate changes and improvements in contraceptive counselling and services in other abortion settings.

Our findings indicate the importance of developing a feedback system to measure women's contraceptive choices and the start of LARC in order to improve access to LARC. The national healthcare system needs to develop a feedback system that facilitates the evaluation of health-promotion activities and prevention in abortion care, to better prevent repeat UPs 


\section{Future research}

The findings of this thesis generated several ideas for future research. It would be of value to study the impact of PCC regarding women's satisfaction with the contraceptive choice, experiences of guidance and access to contraceptive methods post-abortion. Other issues include: how to support women with special needs for contraceptive counselling, in collaboration with other caregivers and women and, further, how to better support sceptical women who have difficulties in finding a contraceptive method at the time of an abortion. It would also be important to study efforts to provide coordinated and early access to LARC as well as aspects of sustainability regarding changes in counselling and services after QICs. Another upcoming opportunity would be to study the feasibility and the benefits of using RLP in contraceptive counselling at the time of an abortion. 


\section{CONCLUSIONS}

Respectful counselling is central to establishing trust in a complex meeting at the time of an abortion (studies II and III). Respectful and skillful counselling influences women's contraceptive choices even if they are sceptical in a charged situation (study II). Guidance and access in the choice of contraceptive method seem to be insufficient at the time of an abortion (study II). Women who choose LARC at the time of an abortion undergo fewer repeat abortions within three to four years compared to women who choose other contraceptive methods, including OC (study I). Women who choose LARC post-abortion need coordinated access to LARC within contraceptive counselling at the time of their abortion (studies II-IV). To collaboratively design and seek to improve counselling and services seems to strengthen HPs' skills in abortion care. Ensuring timely access for women who wish LARC post-abortion remains a challenge in present settings as does the establishing of a feedback system for evaluating counselling and services (study IV). 


\section{SVENSK SAMMANFATTNING}

Preventivmedel ger kvinnor möjligheter att bestämma över sin kropp och reproduktivitet. Att stärka kvinnors kunskap om preventivmedel samt skapa god tillgänglighet till olika preventivmedelsmetoder är centralt när det gäller kvinnors sexuella och reproduktiva rättigheter. Preventivmedelsrådgivning i samband med abort syftar till att stödja kvinnor att finna ett preventivmedel som förebygger upprepad oönskad graviditet. Trots subventionerade preventivmedel, tillhör Sverige de länder i Europa som har den högsta andelen upprepade aborter (45 \%). Preventivmedelsrådgivning anses ha betydelse för preventivmedelsanvändning efter abort. Det är dock fortfarande oklart hur rådgivning ska utformas och organiseras i samband med abort.

Avhandlingens övergripande syfte var att studera kvinnors val av preventivmedel i en svensk population samt beskriva preventivmedelsrådgivning i samband med abort. Sammantaget utgjorde projektets delstudier (studie I-III) grunden för utveckling av förbättringsåtgärder gällande rådgivning och tillgänglighet till preventivmedel i samband med abort. Dessa förbättringsåtgärder studerades i ett systematiskt förbättringsarbete.

Avhandlingen bygger på fyra delstudier med olika design och metoder. Studie I baserades på avidentifierade journaler tillhörande 987 kvinnor. Journaler granskades avseende kvinnors val av preventivmedel i samband med abort och förekomsten av upprepad abort inom 3-4 år. Studie II och III var kvalitativa intervjustudier där tretton kvinnor och hälso och sjukvårdspersonal (barnmorskor och läkare, $\mathrm{n}=21$ ) beskrev sina upplevelser av preventivmedelsrådgivning i samband med abort. Studie IV studerade ett systematiskt förbättringsarbete baserat på fynden i 
studie I-III, där 3 multiprofessionella team inom abortvård deltog. Två kvinnor med personliga erfarenheter medverkade och representerade patientperspektivet.

Resultatet sammanställdes i tre teman;

1. Preventivmedelsrådgivning i samband med abort - ett komplext möte

2. Kvinnors val, behov av vägledning samt tillgänglighet till preventivmedelsmetoder

3. Att utforma och förbättra rådgivning samt tillgänglighet $i$ samband med abort

Preventivmedelsrådgivning i samband med abort beskrevs ofta som ett komplext och emotionellt laddat möte av både kvinnor och hälso och sjukvårdspersonal, i det första temat. Det fanns skeptisism gentemot preventivmedel och en begränsad mottaglighet till information i samband med abort. Respektfullt bemötande var centralt för kvinnorna och underlättade deras val av preventivmedel.

Det andra temat illustrerade kvinnors val, behov av vägledning samt tillgänglighet till preventivmedel. Totalt genomgick 25\% av kvinnorna upprepad abort (er) inom 3-4 år. Val av långtidsverkande preventivmedel såsom spiral och p-stav var associerat med signifikant färre upprepade aborter, jämfört med val av p-piller. Barriärer till spiralanvändning efter abort beskrevs av både kvinnor och hälso och sjukvårdspersonal. Det framkom att kvinnorna hade svårt att nå barnmorskor i kvinnohälsovården för att boka spiralinsättning efter abort. Det fanns kvinnokliniker som inte hade möjlighet att boka tid för spiralinsättning i samband med abort och det fanns begränsad kunskap om spiralinsättning. Det fanns även begränsade möjligheter för hälso och sjukvårdspersonalen att utvärdera preventivmedelsrådgivningen. 
Att delta i ett systematiskt förbättringsarbete med patientmedverkan, föreföll öka hälso och sjukvårdspersonalens kunskaper om preventivmedel samt förmågan att ge rådgivning, enligt det tredje temat. De beskrev även att de fick möjlighet att utvärdera kvinnors val av preventivmedel och tillgänglighet till långtidsverkande preventivmedel. Trots att majoriteten av kvinnorna i förbättringsarbetet valde långtidsverkande preventivmedel, förmådde inget av de deltagande teamen nå det uppsatta målet, att 50\% av kvinnorna skulle få börja med långtidsverkande preventivmedel inom 30 dagar efter abort.

Slutsatsen blev att kvinnor behöver respektfullt bemötande och vägledning vid val av preventivmedel i samband med abort. Tillgänglighet till olika preventivmedelsmetoder behöver utvecklas med fokus på långtidsverkande preventivmedel. Vidare behöver rådgivningen kunna utvärderas vad gäller mötet mellan kvinnan och hälso och sjukvårdspersonalen, i syfte att förebygga upprepade oönskade graviditeter.

\section{Sökord}

Abort, Långtidsverkande preventivmedel, Tillgänglighet, Oönskad graviditet, Patientmedverkan, Preventivmedelsrådgivning, Respekt, Systematiskt förbättringsarbete, Vägledning. 


\section{ACKNOWLEDGEMENTS}

I would like to express my gratitude to all of you who in different ways have inspired and supported me to complete this thesis.

Special thanks go to:

All the women and health professionals who have participated in this thesis. Thank you for sharing your stories.

Professionals at the Departments for Obstetrics and Gynaecology at Norrköping, Linköping, Jönköping, Värnamo and Eksjö Hospital for your help with sampling and data collection.

All my supervisors for creating a fantastic researcher team inspired with learning, humour, kindness and generosity. You have all supported me to grow as a person.

My main supervisor, Siw Alehagen, who opened the door and believed in this issue and in my capacity. Thanks for all your support during this process, for interesting discussions and challenging questions.

My co-supervisor, Jan Brynhildsen, who believed in this issue and in my capacity. Thanks for constructive feedback, and for sharing all your knowledge regarding contraceptive methods and abortion care.

My co-supervisor, Johan Thor, for constructive feedback and sharing knowledge in the field of improvement science and for inspiring me to acquire new English vocabulary.

My co-authors, Carina Berterö and Birgitta Salomonsson, for your contributions and knowledge about qualitative studies.

Boel Gäre Andersson and Martin Rejler, for support during this journey and for introducing me to the fields of co-production and improvement science.

All my doctoral colleagues and the staff at IMH and ISV for interesting discussions and coffee breaks. Special thanks to; Hanna Grundström, for 
challenging questions and support during this time. Lars Sandman, for constructive feedback and discussions regarding ethical considerations.

Mats Fredriksson at Forum Östergötland, for support during statistical analysis.

Staff at Futurum for all your support during my PhD. Special thanks to Anneli Ohlsson and Mikael Wallin.

Staff at Qulturum for all your support during Study IV. Special thanks to Göran Henriks, Eva Werner and Dennis Nordwall.

All my colleagues at the Department of Obstetrics and Gynaecology at Eksjö Hospital for your encouragement and interest in my work.

My parents, Inga-lill and Sören, for all your support and practical help. My sisters, Kristin, Camilla and Evelina, for encouragement and showing interest in the issue. My parents-in-law, Elisabet and Lännart, for all your encouragement and practical help.

My friends for being there and for believing in me. A special thanks to Karin Nolin and Sofie Karlsson, who have supported me during this process.

Last but not least, my husband, Emil, and my children, Lukas, Tova and Kajsa. Emil, you have supported me in this work and made it possible for me to work late nights. You have contributed with challenging questions and new perspectives. Lukas, Tova and Kajsa, for all the much-needed breaks and exciting activities. You have all taught me that, although research is important, there are things in life that mean much more. 


\section{REFERENCES}

1. International Federation of Gynecology and Obstetrics, International Confederation of Midwives, International Council of Nurses, United States Agency for International Development, White Ribbon Alliance, Department for International Development et al. Post abortion family planning: a key component of post abortion care Washington, DC 2013 [cited 3 October 2018]; Available from: https://www.figo.org/sites/default/files/uploads/projectpublications/PAC-FP-Joint-Statement-November2013final printquality.pdf.

2. Benson J, Andersen K, Brahmi D, Healy J, Mark A, Ajode A, et al. What contraception do women use after abortion? An analysis of 319,385 cases from eight countries. Glob Public Health. 2016 May 18:1-16. doi: 10.1080/17441692.2016.1174280.

3. Moreau C, Trussell J, Desfreres J, Bajos N. Patterns of contraceptive use before and after an abortion: results from a nationally representative survey of women undergoing an abortion in France. Contraception. 2010 Oct;82(4):337-44. doi: 10.1016/j.contraception.2010.03.011.

4. Tripney J, Kwan I, Bird KS. Postabortion family planning counseling and services for women in low-income countries: a systematic review. Contraception. 2013 Jan;87(1):17-25. doi:

10.1016/j.contraception.2012.07.014.

5. World Health Organization. Sexual health and its linkages to reproductive health: an operational approach. 2017 [cited 3 October 2018]; Available from:

http://apps.who.int/iris/bitstream/handle/10665/258738/9789241512 886eng.pdf;jsessionid=CoBA7ADA58A02724BE3E382F8F740D30?seq uence $=1$.

6. Folkhälsomyndigheten. Sexuell och reproduktiv hälsa och rättigheter (SRHR). 2018 [cited 3 October, 2018.]; Available from: https://www.folkhalsomyndigheten.se/livsvillkor-levnadsvanor/sexuellhalsa-hivprevention/srhr/.

7. Trussell J, Henry N, Hassan F, Prezioso A, Law A, Filonenko A. Burden of unintended pregnancy in the United States: potential savings with increased use of long-acting reversible contraception. Contraception. 2013 Feb;87(2):154-61. doi: 10.1016/j.contraception.2012.07.016. 
8. Larsson M, Aneblom G, Odlind V, Tyden T. Reasons for pregnancy termination, contraceptive habits and contraceptive failure among Swedish women requesting an early pregnancy termination. Acta Obstet Gynecol Scand. 2002 Jan;81(1):64-71.

9. Aztlan-James EA, McLemore M, Taylor D. Multiple Unintended Pregnancies in U.S. Women: A Systematic Review. Womens Health Issues. $2017 \mathrm{Jul}$ - Aug;27(4):407-13. doi: 10.1016/j.whi.2017.02.002.

10. Alemayehu M, Yebyo H, Medhanyie AA, Bayray A, Fantahun M, Goba GK. Determinants of repeated abortion among women of reproductive age attending health facilities in Northern Ethiopia: a case-control study. BMC Public Health. 2017 Feb 13;17(1):188. doi: 10.1186/s12889-0174106-1.

11. Pestvenidze E, Berdzuli N, Lomia N, Gagua T, Umikashvili L, StrayPedersen B. Repeat induced abortions in Georgia, characteristics of women with multiple pregnancy terminations: secondary analysis of the Reproductive Health Survey 2010. Eur J Obstet Gynecol Reprod Biol. 2016 Oct;205:85-90. doi: 10.1016/j.ejogrb.2016.08.020.

12. McCall SJ, Flett G, Okpo E, Bhattacharya S. Who has a repeat abortion? Identifying women at risk of repeated terminations of pregnancy: analysis of routinely collected health care data. J Fam Plann Reprod Health Care. 2016 Apr;42(2):133-42. doi: 10.1136/jfprhc-2014-101059.

13. Makenzius M, Tyden T, Darj E, Larsson M. Repeat induced abortion - a matter of individual behaviour or societal factors? A cross-sectional study among Swedish women. Eur J Contracept Reprod Health Care. 2011 Oct;16(5):369-77. doi: 10.3109/13625187.2011.595520.

14. Purcell C, Cameron S, Lawton J, Glasier A, Harden J. Contraceptive care at the time of medical abortion: experiences of women and health professionals in a hospital or community sexual and reproductive health context. Contraception. 2016 Feb;93(2):170-7. doi: 10.1016/j.contraception.2015.09.016.

15. Dehlendorf C, Diedrich J, Drey E, Postone A, Steinauer J. Preferences for decision-making about contraception and general health care among reproductive age women at an abortion clinic. Patient Educ Couns. 2010 Dec;81(3):343-8. doi: 10.1016/j.pec.2010.06.021.

16. Stalhandske ML, Makenzius M, Tyden T, Larsson M. Existential experiences and needs related to induced abortion in a group of Swedish women: a quantitative investigation. J Psychosom Obstet Gynaecol. 2012 Jun;33(2):53-61. doi: 10.3109/0167482x.2012.677877. 
17. Lopez LM, Grey TW, Chen M, Tolley EE, Stockton LL. Theory-based interventions for contraception. Cochrane Database Syst Rev. 2016 Nov 23;11:Cdoo7249. doi: 10.1002/14651858.CDo07249.pub5.

18. Ferreira AL, Lemos A, Figueiroa JN, de Souza AI. Effectiveness of contraceptive counselling of women following an abortion: a systematic review and meta-analysis. Eur J Contracept Reprod Health Care. 2009 Feb;14(1):1-9. doi: 10.1080/13625180802549970.

19. Loeber OE, Muntinga ME. Contraceptive counselling for women with multiple unintended pregnancies: the abortion client's perspective. Eur J Contracept Reprod Health Care. 2017 Apr;22(2):94-101. doi: 10.1080/13625187.2017.1283399.

20. Fine JB, Mayall K, Sepulveda L. The Role of International Human Rights Norms in the Liberalization of Abortion Laws Globally. Health Hum Rights. 2017 Jun;19(1):69-80.

21. Giami A. Between DSM and ICD: Paraphilias and the Transformation of Sexual Norms. Arch Sex Behav. 2015 Jul;44(5):1127-38. doi: 10.1007/s10508-015-0549-6.

22. Socialstyrelsen. Underlag till nationell strategi för sexuell och reproduktiv hälsa och rättigheter. 2014 [cited 3 October 2018]; Available from: https://www.socialstyrelsen.se/publikationer2014/2014-10-26.

23. Sedgh G, Bearak J, Singh S, Bankole A, Popinchalk A, Ganatra B, et al. Abortion incidence between 1990 and 2014: global, regional, and subregional levels and trends. Lancet. 2016 May 11 doi: 10.1016/s01406736(16)30380-4.

24. Singh NS, Huicho L, Afnan-Holmes H, John T, Moran AC, Colbourn T, et al. Countdown to 2015 country case studies: systematic tools to address the "black box" of health systems and policy assessment. BMC Public Health. 2016 Sep 12;16 Suppl 2:790. doi: 10.1186/s12889-0163402-5.

25. Wulifan JK, Brenner S, Jahn A, De Allegri M. A scoping review on determinants of unmet need for family planning among women of reproductive age in low and middle income countries. BMC Womens Health. 2016 Jan 15;16:2. doi: 10.1186/s12905-015-0281-3.

26. United Nations. World contraceptive pattern 2013. 2013 [cited 3 October 2018]; Available from: http://www.un.org/en/development/desa/population/publications/pdf ffamily/World-Contraceptive-Patterns-2013 slides.pdf. 
27. Darroch JE WV, Bankole A, Ashford LS,. Adding it Up: Costs and Benefits of Meeting the Contraceptive Needs of Adolescents. New York: Guttmacher Institute; 2016 [cited 3 October 2018]; Available from: https://www.guttmacher.org/sites/default/files/report pdf/adding-itup-adolescents-report.pdf.

28. Huber D, Curtis C, Irani L, Pappa S, Arrington L. Postabortion Care: 20 Years of Strong Evidence on Emergency Treatment, Family Planning, and Other Programming Components. Glob Health Sci Pract. 2016 Sep 28;4(3):481-94. doi: 10.9745/ghsp-d-16-00052.

29. Ganatra B, Gerdts C, Rossier C, Johnson BR, Jr., Tuncalp O, Assifi A, et al. Global, regional, and subregional classification of abortions by safety, 2010-14: estimates from a Bayesian hierarchical model. Lancet. 2017 Nov 25;390(10110):2372-81. doi: 10.1016/s0140-6736(17)31794-4.

30. Say L, Chou D, Gemmill A, Tuncalp O, Moller AB, Daniels J, et al. Global causes of maternal death: a WHO systematic analysis. Lancet Glob Health. 2014 Jun;2(6):e323-33. doi: 10.1016/s2214-109x(14)70227-x.

31. Horga M, Gerdts C, Potts M. The remarkable story of Romanian women's struggle to manage their fertility. J Fam Plann Reprod Health Care. 2013 Jan;39(1):2-4. doi: 10.1136/jfprhc-2012-100498.

32. Sedgh G, Singh S, Hussain R. Intended and unintended pregnancies worldwide in 2012 and recent trends. Stud Fam Plann. 2014 Sep;45(3):301-14. doi: 10.1111/j.1728-4465.2014.00393.x.

33. Henry N, Hawes C, Lowin J, Lekander I, Filonenko A, Kallner HK. Costeffectiveness analysis of a low-dose contraceptive levonorgestrel intrauterine system in Sweden. Acta Obstet Gynecol Scand. 2015 Aug;94(8):884-90. doi: 10.1111/aogs.12679.

34. Aghaei F, Shaghaghi A, Sarbakhsh P. A systematic review of the research evidence on cross-country features of illegal abortions. Health Promot Perspect. 2017;7(3):117-23. doi: 10.15171/hpp.2017.22.

35. Jayaweera RT, Ngui FM, Hall KS, Gerdts C. Women's experiences with unplanned pregnancy and abortion in Kenya: A qualitative study. PLoS One. 2018;13(1):e0191412. doi: 10.1371/journal.pone.0191412.

36. Socialstyrelsen. Abortstatistik. 2017 [cited 3 October 2018 ]; Available from: https://www.socialstyrelsen.se/publikationer2018/2018-5-17.

37. United Kingdom Government. Report on abortion statistics in England and Wales for 20172017 [cited 3 October 2018]; Available from: https://assets.publishing.service.gov.uk/government/uploads/system/u ploads/attachment data/file/714183/2017 Abortion Statistics Comm entary.pdf. 
38. Jones R, Jerman J, Ingerick M. Which Abortion Patients Have Had a Prior Abortion? Findings from the 2014 U.S. Abortion Patient Survey. J Womens Health (Larchmt). 2017 Aug 23 doi: 10.1089/jwh.2017.6410.

39. Toprani A, Cadwell BL, Li W, Sackoff J, Greene C, Begier E. Repeat abortions in New York City, 2010. J Urban Health. 2015 Jun;92(3):593603. doi: 10.1007/s11524-015-9946-3.

40. National Services Scotland. Termination of Pregnancy, Sexual Health. 2017 [cited 3 October 2018]; Available from: http://www.isdscotland.org/Health-Topics/Sexual-Health/Abortions/.

41. Heikinheimo O, Gissler M, Suhonen S. Age, parity, history of abortion and contraceptive choices affect the risk of repeat abortion.

Contraception. 2008 Aug;78(2):149-54. doi: 10.1016/j.contraception.2008.03.013.

42. Goodman S, Hendlish SK, Reeves MF, Foster-Rosales A. Impact of immediate postabortal insertion of intrauterine contraception on repeat abortion. Contraception. 2008 Aug;78(2):143-8. doi: 10.1016/j.contraception.2008.03.003.

43. Maina BW, Mutua MM, Sidze EM. Factors associated with repeat induced abortion in Kenya. BMC Public Health. 2015 Oct 12;15:1048. doi: 10.1186/s12889-015-2400-3.

44. Picavet C, Goenee M, Wijsen C. Characteristics of women who have repeat abortions in the Netherlands. Eur J Contracept Reprod Health Care. 2013 Oct;18(5):327-34. doi: 10.3109/13625187.2013.820824.

45. Vangen S, Eskild A, Forsen L. Termination of pregnancy according to immigration status: a population-based registry linkage study. BJOG. 2008 Sep;115(10):1309-15. doi: 10.1111/j.1471-0528.2008.01832.x.

46. Goldstone P, Mehta YH, McGeechan K, Francis K, Black KI. Factors predicting uptake of long-acting reversible methods of contraception among women presenting for abortion. Med J Aust. 2014 Oct 6;201(7):412-6.

47. Dehlendorf C, Park SY, Emeremni CA, Comer D, Vincett K, Borrero S. Racial/ethnic disparities in contraceptive use: variation by age and women's reproductive experiences. Am J Obstet Gynecol. 2014 Jun;210(6):526 e1-9. doi: 10.1016/j.ajog.2014.01.037.

48. Poncet LC, Huang N, Rei W, Lin YC, Chen CY. Contraceptive use and method among immigrant women in France: relationship with socioeconomic status. Eur J Contracept Reprod Health Care. 2013 Dec;18(6):468-79. doi: 10.3109/13625187.2013.835394. 
49. Omland G, Ruths S, Diaz E. Use of hormonal contraceptives among immigrant and native women in Norway: data from the Norwegian Prescription Database. BJOG. 2014 Sep;121(10):1221-8. doi: 10.1111/1471-0528.12906.

50. Gomez AM, Wapman M. Under (implicit) pressure: young Black and Latina women's perceptions of contraceptive care. Contraception. 2017 Oct;96(4):221-6. doi: 10.1016/j.contraception.2017.07.007.

51. Thorburn S, Bogart LM. African American women and family planning services: perceptions of discrimination. Women Health. 2005;42(1):2339. doi: 10.1300/Jo13V42no1_02.

52. Downing RA, LaVeist TA, Bullock HE. Intersections of ethnicity and social class in provider advice regarding reproductive health. Am J Public Health. 2007 Oct;97(10):1803-7. doi: 10.2105/ajph.2006.092585.

53. Laanpere M, Ringmets I, Part K, Allvee K, Veerus P, Karro H. Abortion trends from 1996 to 2011 in Estonia: special emphasis on repeat abortion. BMC Womens Health. 2014 Jul 09;14:81. doi: 10.1186/14726874-14-81.

54. Purcell C, Riddell J, Brown A, Cameron S, Melville C, Flett G, et al. Women's experiences of more than one termination of pregnancy within two years: a mixed-methods study. BJOG. 2017 Sep 18 doi: 10.1111/14710528.14940.

55. Lie ML, Robson SC, May CR. Experiences of abortion: a narrative review of qualitative studies. BMC Health Serv Res. 2008;8:150. doi: 10.1186/1472-6963-8-150.

56. Andersson IM, Christensson K, Gemzell-Danielsson K. Experiences, feelings and thoughts of women undergoing second trimester medical termination of pregnancy. PLoS One. 2014;9(12):e115957. doi: 10.1371/journal.pone.0115957.

57. Hallden BM, Christensson K, Olsson P. Early abortion as narrated by young Swedish women. Scand J Caring Sci. 2009 Jun;23(2):243-50. doi: 10.1111/j.1471-6712.2008.00612.x.

58. Biggs MA, Upadhyay UD, McCulloch CE, Foster DG. Women's Mental Health and Well-being 5 Years After Receiving or Being Denied an Abortion: A Prospective, Longitudinal Cohort Study. JAMA Psychiatry. 2017 Feb 01;74(2):169-78. doi: 10.1001/jamapsychiatry.2016.3478.

59. Foster DG. Unmet need for abortion and woman-centered contraceptive care. Lancet. 2016 Jul 16;388(10041):216-7. doi: 10.1016/s01406736(16)30452-4. 
6o. Ballou M, Fetter M, Saleh K, Litwack L. Health Counseling. Ohio: American School Health Association; 1992.

61. Weisman C, Maccannon S, Henderson T, Shortridge E, Orso L. Contraceptive Counseling in Managed Care: Preventing Unintended Pregnancy in Adults. Womens Health Issues. 2002;Mar-Apr;12(2):7995.

62. Dehlendorf C, Krajewski C, Borrero S. Contraceptive counseling: best practices to ensure quality communication and enable effective contraceptive use. Clin Obstet Gynecol. 2014 Dec;57(4):659-73. doi: 10.1097/grf.0000000000000059.

63. Dehlendorf C, Henderson JT, Vittinghoff E, Grumbach K, Levy K, Schmittdiel J, et al. Association of the quality of interpersonal care during family planning counseling with contraceptive use. Am J Obstet Gynecol. 2016 Jan 28 doi: 10.1016/j.ajog.2016.01.173.

64. Brandi K, Woodhams E, White KO, Mehta PK. An exploration of perceived contraceptive coercion at the time of abortion. Contraception. 2017 Dec 15 doi: 10.1016/j.contraception.2017.12.009.

65. Downey MM, Arteaga S, Villasenor E, Gomez AM. More Than a Destination: Contraceptive Decision Making as a Journey. Womens Health Issues. 2017 Sep - Oct;27(5):539-45. doi: 10.1016/j.whi.2017.03.004.

66. Scott RH, Bajos N, Slaymaker E, Wellings K, Mercer CH. Understanding differences in conception and abortion rates among under-20 year olds in Britain and France: Examining the contribution of social disadvantage. PLoS One. 2017;12(10):e0186412. doi: 10.1371/journal.pone.0186412.

67. Pazol K, Whiteman MK, Folger SG, Kourtis AP, Marchbanks PA, Jamieson DJ. Sporadic contraceptive use and nonuse: age-specific prevalence and associated factors. Am J Obstet Gynecol. 2015 Mar;212(3):324.e1-8. doi: 10.1016/j.ajog.2014.10.004.

68. Sedgh G, Hussain R. Reasons for contraceptive nonuse among women having unmet need for contraception in developing countries. Stud Fam Plann. 2014 Jun;45(2):151-69. doi: 10.1111/j.1728-4465.2014.00382.x.

69. Mosher W, Jones J, Abma J. Nonuse of contraception among women at risk of unintended pregnancy in the United States. Contraception. 2015 Aug;92(2):170-6. doi: 10.1016/j.contraception.2015.05.004.

70. Lindh I, Hognert H, Milsom I. The changing pattern of contraceptive use and pregnancies in four generations of young women. Acta Obstet Gynecol Scand. 2016 Nov;95(11):1264-72. doi: 10.1111/aogs.13003. 
71. Lindh I, Ellstrom AA, Blohm F, Milsom I. A longitudinal study of contraception and pregnancies in the same women followed for a quarter of a century. Hum Reprod. 2010 Jun;25(6):1415-22. doi: 10.1093/humrep/deq095.

72. Nobili MP, Piergrossi S, Brusati V, Moja EA. The effect of patientcentered contraceptive counseling in women who undergo a voluntary termination of pregnancy. Patient Educ Couns. 2007 Mar;65(3):361-8. doi: 10.1016/j.pec.2006.09.004.

73. Whitaker AK, Quinn MT, Munroe E, Martins SL, Mistretta SQ, Gilliam ML. A motivational interviewing-based counseling intervention to increase postabortion uptake of contraception: A pilot randomized controlled trial. Patient Educ Couns. 2016 Oct;99(10):1663-9. doi: 10.1016/j.pec.2016.05.011.

74. Wyatt KD, Anderson RT, Creedon D, Montori VM, Bachman J, Erwin P, et al. Women's values in contraceptive choice: a systematic review of relevant attributes included in decision aids. BMC Womens Health. 2014 Feb 13;14(1):28. doi: 10.1186/1472-6874-14-28.

75. Donnelly KZ, Foster TC, Thompson R. What matters most? The content and concordance of patients' and providers' information priorities for contraceptive decision making. Contraception. 2014 Sep;90(3):280-7. doi: 10.1016/j.contraception.2014.04.012.

76. Fait T, Buryak D, Cirstoiu MM, Luczai E, Janczura R. Needs and preferences of women users of oral contraceptives in selected countries in Central and Eastern Europe. Drugs Context. 2018;7:212510. doi: 10.7573/dic.212510.

77. Kopp Kallner H, Thunell L, Brynhildsen J, Lindeberg M, Gemzell Danielsson K. Use of Contraception and Attitudes towards Contraceptive Use in Swedish Women--A Nationwide Survey. PLoS One. 2015;10(5):e0125990. doi: 10.1371/journal.pone.0125990.

78. Gemzell-Danielsson K, Thunell L, Lindeberg M, Tyden T, MarintchevaPetrova M, Oddens BJ. Comprehensive counseling about combined hormonal contraceptives changes the choice of contraceptive methods: results of the CHOICE program in Sweden. Acta Obstet Gynecol Scand. 2011 Aug;90(8):869-77. doi: 10.1111/j.1600-0412.2011.01180.x.

79. Falk G, Ivarsson AB, Brynhildsen J. Teenagers' struggles with contraceptive use - what improvements can be made? Eur J Contracept Reprod Health Care. 2010 Aug;15(4):271-9. doi: $10.3109 / 13625187.2010 .493623$. 
80. Michie L, Cameron ST, Glasier A, Wellings K, Loudon J. Myths and misconceptions about intrauterine contraception among women seeking termination of pregnancy. J Fam Plann Reprod Health Care. 2014 Jan;4O(1):36-40. doi: 10.1136/jfprhc-2012-100497.

81. Rose SB, Cooper AJ, Baker NK, Lawton B. Attitudes toward long-acting reversible contraception among young women seeking abortion. J Womens Health (Larchmt). 2011 Nov;20(11):1729-35. doi: $10.1089 /$ jwh.2010.2658.

82. Keene M, Roston A, Keith L, Patel A. Effect of previous induced abortions on postabortion contraception selection. Contraception. 2015 May;91(5):398-402. doi: 10.1016/j.contraception.2014.10.011.

83. Schreiber CAS, S. Ratcliffe,S. \& Creinin,M.D Ovulation resumption after medical abortion with mifepristone and misoprostol. Contraception. 2011;84(3):230-3.

84. Lahteenmaki P LT. Return of ovarian function after abortion. Clin Endocrinol. 1978;8:123-32.

85. Saav I, Stephansson O, Gemzell-Danielsson K. Early versus delayed insertion of intrauterine contraception after medical abortion - a randomized controlled trial. PLoS One. 2012;7(11):e48948. doi: 10.1371/journal.pone.0048948.

86. Kavanaugh ML, Carlin EE, Jones RK. Patients' attitudes and experiences related to receiving contraception during abortion care. Contraception. 2011 Dec;84(6):585-93. doi: 10.1016/j.contraception.2011.03.009.

87. Munk-Olsen T, Laursen TM, Pedersen CB, Lidegaard O, Mortensen PB. Induced first-trimester abortion and risk of mental disorder. $\mathrm{N}$ Engl $\mathrm{J}$ Med. 2011 Jan 27;364(4):332-9. doi: 10.1056/NEJMoa0905882.

88. Leppalahti S, Heikinheimo O, Kalliala I, Santalahti P, Gissler M. Is underage abortion associated with adverse outcomes in early adulthood? A longitudinal birth cohort study up to 25 years of age. Hum Reprod. 2016 Sep;31(9):2142-9. doi: 10.1093/humrep/dew178.

89. Toffol E, Pohjoranta E, Suhonen S, Hurskainen R, Partonen T, Mentula $\mathrm{M}$, et al. Anxiety and quality of life after first-trimester termination of pregnancy: a prospective study. Acta Obstet Gynecol Scand. 2016 Oct;95(10):1171-80. doi: 10.1111/aogs.12959.

90. Steinberg JR, Tschann JM, Furgerson D, Harper CC. Psychosocial factors and pre-abortion psychological health: The significance of stigma. Soc Sci Med. 2016 Feb;150:67-75. doi: 10.1016/j.socscimed.2015.12.007. 
91. Hoggart L, Newton VL, Bury L. 'Repeat abortion', a phrase to be avoided? Qualitative insights into labelling and stigma. J Fam Plann Reprod Health Care. 2017 Jan;43(1):26-30. doi: 10.1136/jfprhc-2016101487.

92. Gomez AM, Fuentes L, Allina A. Women or LARC first? Reproductive autonomy and the promotion of long-acting reversible contraceptive methods. Perspect Sex Reprod Health. 2014 Sep;46(3):171-5. doi: $10.1363 / 46 \mathrm{e} 1614$.

93. United Nations. World Family Planning. 2017 [cited 3 October 2018]; Available from: http://www.un.org/en/development/desa/population/publications/pdf /family/WFP2017_Highlights.pdf.

94. Ross J, Hardee K. Use of male methods of contraception worldwide. J Biosoc Sci. 2017 Sep;49(5):648-63. doi: 10.1017/s0021932016000560.

95. Kavanaugh ML, Jerman J. Contraceptive method use in the United States: trends and characteristics between 2008, 2012 and 2014. Contraception. 2018 Jan;97(1):14-21. doi: 10.1016/j.contraception.2017.10.003.

96. Lindh I, Skjeldestad FE, Gemzell-Danielsson K, Heikinheimo O, Hognert H, Milsom I, et al. Contraceptive use in the Nordic countries. Acta Obstet Gynecol Scand. 2017 Jan;96(1):19-28. doi: 10.1111/aogs.13055.

97. Trussell J. Understanding contraceptive failure. Best Pract Res Clin Obstet Gynaecol. 2009 Apr;23(2):199-209. doi: 10.1016/j.bpobgyn.2008.11.008.

98. Sundaram A, Vaughan B, Kost K, Bankole A, Finer L, Singh S, et al. Contraceptive Failure in the United States: Estimates from the 20062010 National Survey of Family Growth. Perspect Sex Reprod Health. 2017 Mar;49(1):7-16. doi: 10.1363/psrh.12017.

99. Läkemedelsverket. Antikonception - behandlingsrekommendation. 2014;25(2):14-28. 2014 [cited 3 October 2018]; Available from: https://lakemedelsverket.se/upload/halso-ochsjukvard/behandlingsrekommendationer/Antikonception rek.pdf.

100. Edelman A, Micks E, Gallo MF, Jensen JT, Grimes DA. Continuous or extended cycle vs. cyclic use of combined hormonal contraceptives for contraception. Cochrane Database Syst Rev. 2014 Jul 29(7):CDo04695. doi: 10.1002/14651858.CDo04695.pub3.

101. Grimes DA. Forgettable contraception. Contraception. 2009 Dec;80(6):497-9. doi: 10.1016/j.contraception.2009.06.005. 
102. Peipert JF, Zhao Q, Allsworth JE, Petrosky E, Madden T, Eisenberg D, et al. Continuation and satisfaction of reversible contraception. Obstet Gynecol. 2011 May;117(5):1105-13. doi:

10.1097/AOG.obo13e31821188ad.

103. Iversen L, Sivasubramaniam S, Lee AJ, Fielding S, Hannaford PC. Lifetime cancer risk and combined oral contraceptives: the Royal College of General Practitioners' Oral Contraception Study. Am J Obstet Gynecol. 2017 Jun;216(6):580 e1- e9. doi: 10.1016/j.ajog.2017.02.002.

104. Cameron ST, Glasier A, Chen ZE, Johnstone A, Dunlop C, Heller R. Effect of contraception provided at termination of pregnancy and incidence of subsequent termination of pregnancy. BJOG. 2012 Aug;119(9):1074-80. doi: 10.1111/j.1471-0528.2012.03407.x.

105. Rose SB, Lawton BA. Impact of long-acting reversible contraception on return for repeat abortion. Am J Obstet Gynecol. 2012 Jan;206(1):37 e16. doi: 10.1016/j.ajog.2011.06.102.

106. Barros Pereira I, Carvalho RM, Graca LM. Intra-abortion contraception with etonogestrel subdermal implant. Eur J Obstet Gynecol Reprod Biol. 2015 Feb;185:33-5. doi: 10.1016/j.ejogrb.2014.11.025.

107. Hognert H, Kopp Kallner H, Cameron S, Nyrelli C, Jawad I, Heller R, et al. Immediate versus delayed insertion of an etonogestrel releasing implant at medical abortion-a randomized controlled equivalence trial. Hum Reprod. 2016 Sep 22 doi: 10.1093/humrep/dew238.

108. Socialstyrelsen. Vård vid förlossning och gynekologiska sjukdomar. 2009 [cited 3 October 2018]; Available from: http://www.socialstyrelsen.se/publikationer2009/2009-12672/Documents/Utveckling\%20V\%C3\%A5rd\%20vid\%20f\%C3\%B6rlossn ing\%20och\%20gynekologiska\%20sjukdomar.pdf.

109. Svensk förening för Obstetrik och Gynekologi. Inducerad abort, Uppsala ,2018.

110. Regeringskansliet. Sveriges internationella politik för sexuell och reproduktiv hälsa. 2006 [cited 3 October 2018]; Available from: http://www.regeringen.se/informationsmaterial/2006/02/sverigesinternationella-politik-for-sexuell-och-reproduktiv-halsa/.

111. Sveriges Kommuner och Landsting. Jämlika regler för preventivmedel efter SKL:s beslut. 2014 [cited 20183 October]; Available from: https://skl.se/tjanster/press/nyheter/arkiveradenyheter/jamlikareglerf orpreventivmedeleftersklsbeslut.4395.html.

112. Danielsson M, Berglund T, Forsberg M, Larsson M, Rogala C, Tyden T. Sexual and reproductive health: Health in Sweden: The National Public 
Health Report 2012. Chapter 9. Scand J Public Health. 2012 Dec;40(9 Suppl):176-96. doi: 10.1177/1403494812459600.

113. Socialstyrelsen. Socialstyrelsens föreskrifter om abort (SOSFS 2009:15). 2009 [cited 3 October 2018]; Available from: http://www.socialstyrelsen.se/sosfs/2009-15.

114. Sveriges Riksdag. Abortlag (1974:595),Svensk författningssamling 1975 [cited 3 October 2018]; Available from:

https://www.riksdagen.se/sv/dokument-lagar/dokument/svenskforfattningssamling/abortlag-1974595 sfs-1974-595.

115. Milton A. Bättre förutsättningar för det förebyggande arbetetidépromemoria från Socialdepartementets arbetsgrupp för förebyggande av oönskade graviditeter: Socialdepartementet (S 2007:D); 2009.

116. Langley GJ, Moen, R., Nolan, K. M., Nolan, T. W., Norman, C. L., \& Provost, L. P. . The improvement guide : a practical approach to enhancing organizational performance (2nd ed.). ed: San Francisco: Jossey-Bass.; 2009.

117. Berwick DM. A primer on leading the improvement of systems. BMJ. 1996 Mar 9;312(7031):619-22.

118. Grol R, Grimshaw J. From best evidence to best practice: effective implementation of change in patients' care. Lancet. 2003 Oct 11;362(9391):1225-30. doi: 10.1016/s0140-6736(03)14546-1.

119. Nilsen P. Making sense of implementation theories, models and frameworks. Implement Sci. 2015 Apr 21;10:53. doi: 10.1186/s13012015-0242-0.

120. Eldh AC, Almost J, DeCorby-Watson K, Gifford W, Harvey G, Hasson H, et al. Clinical interventions, implementation interventions, and the potential greyness in between -a discussion paper. BMC Health Serv Res. 2017 Jan 7;17(1):16. doi: 10.1186/s12913-016-1958-5.

121. Batalden PB, Davidoff $F$. What is "quality improvement" and how can it transform healthcare? Qual Saf Health Care. 2007 Feb;16(1):2-3. doi: 10.1136/qshc.2006.022046.

122. Kilo CM. A framework for collaborative improvement: lessons from the Institute for Healthcare Improvement's Breakthrough Series. Qual Manag Health Care. 1998 Sep;6(4):1-13.

123. Silva de D. No. 21 Improvement Collaboratives in Health Care. The Evidence Centra, editor. London: The Health Foundation; 2014. 
124. Peterson A, Hanberger L, Akesson K, Bojestig M, Andersson Gare B, Samuelsson U. Improved results in paediatric diabetes care using a quality registry in an improvement collaborative: a case study in Sweden. PLoS One. 2014;9(5):e97875. doi: 10.1371/journal.pone.0097875.

125. Peterson A, Gudbjornsdottir S, Lofgren UB, Schioler L, Bojestig M, Thor $\mathrm{J}$, et al. Collaboratively Improving Diabetes Care in Sweden Using a National Quality Register: Successes and Challenges-A Case Study. Qual Manag Health Care. 2015 Oct-Dec;24(4):212-21. doi: 10.1097/QMH.0000000000000068.

126. Loyola Briceno AC, Kawatu J, Saul K, DeAngelis K, Frederiksen B, Moskosky SB, et al. From theory to application: using performance measures for contraceptive care in the Title $\mathrm{X}$ family planning program. Contraception. 2017 Sep;96(3):166-74. doi: 10.1016/j.contraception.2017.06.009.

127. Greenhalgh T HC, Woodard F,. User involvement in health care. Chichester, West Sussex, UK: Wiley-Blackwell; 2011.

128. Liabo K, Boddy K, Burchmore H, Cockcroft E, Britten N. Clarifying the roles of patients in research. BMJ. 2018 Apr 10;361:k1463. doi: 10.1136/bmj.k1463.

129. Batalden M, Batalden P, Margolis P, Seid M, Armstrong G, OpipariArrigan L, et al. Coproduction of healthcare service. BMJ Qual Saf. 2015 Sep 16 doi: 10.1136/bmjqs-2015-004315.

130. Statens Beredning för Medicinsk och Social Utvärdering.

Patientdelaktighet i hälso- och sjukvården, rapport 260/2017. 2017 [cited 3 October 2018]; Available from: https://www.sbu.se/contentassets/4065ec45dfgc4859852d2e 358d5b8d c6/patientdelaktighet_i_halso_och_sjukvarden.pdf.

131. Ekman I, Swedberg K, Taft C, Lindseth A, Norberg A, Brink E, et al. Person-centered care--ready for prime time. Eur J Cardiovasc Nurs. 2011 Dec;10(4):248-51. doi: 10.1016/j.ejcnurse.2011.06.008.

132. McCormack B, Borg M, Cardiff S, Dewing J, Jacobs G, Janes N, et al. Person-centredness - the 'state' of the art. 2017 [cited 19 October 2018]; Available from: https://www.fons.org/library/journal/volume5-personcentredness-suppl/article1.

133. World Health Organization. Health promotion and disease prevention through population-based interventions, including action to address social determinants and health inequity. 2018 [cited 3 October 2018]; Available from: http://www.emro.who.int/about-who/public-healthfunctions/health-promotion-disease-prevention.html. 
134. Gordon RS, Jr. An operational classification of disease prevention. Public Health Rep. 1983;98:107-9.

135. Trussell J, Guthrie K. Lessons from the contraceptive CHOICE project: the Hull long-acting reversible contraception (LARC) initiative. J Fam Plann Reprod Health Care. 2015 Jan;41(1):60-3. doi: 10.1136/jfprhc2014-100944.

136. McNicholas C, Madden T, Secura G, Peipert JF. The contraceptive CHOICE project round up: what we did and what we learned. Clin Obstet Gynecol. 2014 Dec;57(4):635-43. doi: 10.1097/grf.0000000000000070.

137. Sundstrom B, Szabo C, Dempsey A. "My Body. My Choice": A Qualitative Study of the Influence of Trust and Locus of Control on Postpartum Contraceptive Choice. J Health Commun. 2018;23(2):162-9. doi: 10.1080/10810730.2017.1421728.

138. The Health Foundation. Person-centredcare made simple. What everyone should know about person-centred care. 2014 [cited 2018 June 28]; Available from:

https://www.health.org.uk/sites/health/files/PersonCentredCareMadeS imple.pdf.

139. Hakansson Eklund J, Holmstrom IK, Kumlin T, Kaminsky E, Skoglund $\mathrm{K}$, Hoglander J, et al. "Same same or different?" A review of reviews of person-centered and patient-centered care. Patient Educ Couns. 2018 Aug 26 doi: 10.1016/j.pec.2018.08.029.

140. Elwyn G, Dehlendorf C, Epstein RM, Marrin K, White J, Frosch DL. Shared decision making and motivational interviewing: achieving patient-centered care across the spectrum of health care problems. Ann Fam Med. 2014 May-Jun;12(3):270-5. doi: 10.1370/afm.1615.

141. Whitaker AK, Quinn MT, Martins SL, Tomlinson AN, Woodhams EJ, Gilliam M. Motivational interviewing to improve postabortion contraceptive uptake by young women: development and feasibility of a counseling intervention. Contraception. 2015 Oct;92(4):323-9. doi: 10.1016/j.contraception.2015.06.015.

142. Miller WR, Rollnick S. Motivational Interviewing: Helping People Change. 3rd ed: Guilford Press; 2013.

143. El-Alti L, Sandman L, Munthe C. Person Centered Care and Personalized Medicine: Irreconcilable Opposites or Potential Companions? Health Care Anal. 2017 Sep 21 doi: 10.1007/s10728-017-0347-5. 
144. Sandman L, Munthe C. Shared decision making, paternalism and patient choice. Health Care Anal. 2010 Mar;18(1):60-84. doi: 10.1007/s10728-008-0108-6.

145. Rose SB, Garrett SM. Postabortion Initiation of Long-Acting Reversible Contraception by Adolescent and Nulliparous Women in New Zealand. J Adolesc Health. 2016 Feb;58(2):160-6. doi: 10.1016/j.jadohealth.2015.09.025.

146. Mingers J. Combining IS research methods: Towards a Pluralistic Methodology. Information Systems Research. 2001;12(3):240-59.

147. Reichardt C, S., Rallis S, F. The relationship between the qualitative and quantitative research traditions. Jossey-Bass. 1994:5-11.

148. Socialstyrelsen. Statistikdatabas för aborter. 2017 [cited 3 October 2018]; Available from:

http://www.socialstyrelsen.se/statistik/statistikdatabas/abort.

149. Oates J. Use of Skype in interviews: the impact of the medium in a study of mental health nurses. Nurse Res. 2015 Mar;22(4):13-7. doi: 10.7748/nr.22.4.13.e1318.

150. Yin R. Case study research: design and methods. 4th ed. Los Angeles: Sage publications 2009.

151. Provost LP. Analytical studies: a framework for quality improvement design and analysis. BMJ Qual Saf. 2011 Apr;20 Suppl 1:i92-6. doi: 10.1136/bmjqs.2011.051557.

152. Provost LP, \& Murray,S.K,. the health care data guide:learning from data for improvement. 1st ed ed. San Fransisco CA,: Jossey-Bass; 2011.

153. Thor J, Lundberg J, Ask J, Olsson J, Carli C, Harenstam KP, et al. Application of statistical process control in healthcare improvement: systematic review. Qual Saf Health Care. 2007 Oct;16(5):387-99. doi: 10.1136/qshc.2006.022194.

154. Mohammed MA, Worthington P, Woodall WH. Plotting basic control charts: tutorial notes for healthcare practitioners. Qual Saf Health Care. 2008 Apr;17(2):137-45. doi: 10.1136/qshc.2004.012047.

155. Moustakas C. Phenomenological research methods: Thousand Oaks, Sage publications; 1994.

156. Patton Q, Michael,. Qualitative research and evaluation methods: Thousands Oaks, Sage Publications; 2002. 
157. Hsieh HF, Shannon SE. Three approaches to qualitative content analysis. Qual Health Res. 2005 Nov;15(9):1277-88. doi: $10.1177 / 1049732305276687$.

158. Bennett B PL. What's YOUR Theory? . Quality Progress. 2015;48(7):3643.

159. Svensson L, Ellström P-E, Brulin G. Introduction- on interactive research. 2007 [cited 3 October 2018]; Available from:

http://www.ssoar.info/ssoar/bitstream/handle/document/35635/ssoar -ijar-2007-3-svensson et alIntroduction on Interactive Research.pdf?sequence $=1$.

16o. World Medical Association. WMA Declaration of Helsinki - Ethical Principles for Medical Research Involving Human Subjects 2017 [cited 3 October 2018]; Available from: https://www.wma.net/policiespost/wma-declaration-of-helsinki-ethical-principles-for-medicalresearch-involving-human-subjects/.

161. Kero A, Lalos A. Increased contraceptive use one year post-abortion. Hum Reprod. 2005 Nov;20(11):3085-90. doi: 10.1093/humrep/dei187.

162. Leeners B, Bieli S, Huang D, Tschudin S. Why prevention of repeat abortion is so challenging: psychosocial characteristics of women at risk. Eur J Contracept Reprod Health Care. 2017 Feb;22(1):38-44. doi: 10.1080/13625187.2016.1258053.

163. Larsson EC, Fried S, Essen B, Klingberg-Allvin M. Equitable abortion care - A challenge for health care providers. Experiences from abortion care encounters with immigrant women in Stockholm, Sweden. Sex Reprod Healthc. 2016 Dec;10:14-8. doi: 10.1016/j.srhc.2016.10.003.

164. Morse J, Freedman L, Speidel JJ, Thompson KM, Stratton L, Harper CC. Postabortion Contraception: Qualitative Interviews On Counseling and Provision of Long-Acting Reversible Contraceptive Methods. Perspect Sex Reprod Health. 2012 Jun;44(2):100-6. doi: 10.1363/4410012.

165. Russo JA, Miller E, Gold MA. Myths and misconceptions about longacting reversible contraception (LARC). J Adolesc Health. 2013 Apr;52(4 Suppl):S14-21. doi: 10.1016/j.jadohealth.2013.02.003.

166. Gemzell-Danielsson K, Cho S, Inki P, Mansour D, Reid R, Bahamondes L. Use of contraceptive methods and contraceptive recommendations among health care providers actively involved in contraceptive counseling - results of an international survey in 10 countries. Contraception. 2012 Jul 6 doi: 10.1016/j.contraception.2012.06.002. 
167. Singal AG, Higgins PD, Waljee AK. A primer on effectiveness and efficacy trials. Clin Transl Gastroenterol. 2014 Jan 2;5:e45. doi: 10.1038/ctg.2013.13.

168. Potter L, Oakley D, de Leon-Wong E, Canamar R. Measuring compliance among oral contraceptive users. Fam Plann Perspect. 1996 JulAug;28(4):154-8.

169. RamaRao S LM, Costello M, Pangolibay B, Jones H. The link between quality of care and contraceptive use. Int Fam Plan Perspect 2003;29(2):76-83. doi: PMID:12783771.

170. Morse JE, Moos MK. Reproductive Life Planning: Raising the Questions. Matern Child Health J. 2018 Mar 6 doi: 10.1007/s10995-018-2516-z.

171. Black KI, Geary R, French R, Leefe N, Mercer CH, Glasier A, et al. Trends in the use of emergency contraception in Britain: evidence from the second and third National Surveys of Sexual Attitudes and Lifestyles. BJOG. 2016 Sep;123(10):1600-7. doi: 10.1111/1471-0528.14131.

172. Sannisto T, Saaristo V, Stahl T, Mattila K, Kosunen E. Quality of the contraceptive service structure: a pilot study in Finnish health centre organisations. Eur J Contracept Reprod Health Care. 2010 Aug;15(4):243-54. doi: 10.3109/13625187.2010.500750.

173. Tistad M, Palmcrantz S, Wallin L, Ehrenberg A, Olsson CB, Tomson G, et al. Developing Leadership in Managers to Facilitate the Implementation of National Guideline Recommendations: A Process Evaluation of Feasibility and Usefulness. Int J Health Policy Manag. 2016 Apr 11;5(8):477-86. doi: 10.15171/ijhpm.2016.35.

174. Baker GR. The contribution of case study research to knowledge of how to improve quality of care. BMJ Qual Saf. 2011 Apr;20 Suppl 1:i3o-5. doi: 10.1136/bmjqs.2010.046490.

175. Morse J, Barret, M, Mayan, M, Olson, K, Spiers J. . Verification strategies for establishing reliability and validity in qualitative research. Int J Qual methods 2002;1(2):13-22.

176. Silverman D. Interpreting qualitative data. 4th ed. London: Sage; 2011.

177. Brinkmann S \& Kvale S. Interviews - learning the Craft of Qualitative Research Interviewing: Sage 2015. 


\section{Appendix 1. Programme for learning sessions during QIC 2017}

\begin{tabular}{|c|c|c|c|}
\hline $\begin{array}{l}\text { Session } \\
\text { /month }\end{array}$ & Theme for the session & Activities at the session & Homework \\
\hline $\begin{array}{l}\text { Learning } \\
\text { session } 1 \\
\text { March }\end{array}$ & $\begin{array}{l}\text { Why do we need to do this? } \\
\text { Lectures and Discussion } \\
\text { Relevant research from the project and } \\
\text { field } \\
\text {-Local statistics -repeat abortion rates - } \\
\text { use of LARC. } \\
\text { Introduction of four drivers. To set goals } \\
\text { for the QIC: } \\
\text { What do we want to accomplish? } \\
\text { How to work in a team. } \\
\text { Introduction to tools in QI. }\end{array}$ & $\begin{array}{l}\text { Lectures and Discussions } \\
\text { Start to identify obstacles } \\
\text { Teams' experiences of working with the } \\
\text { drivers at each department } \\
\text { Discussion and introduction to decision aids } \\
\text { in contraceptive counselling regarding } \\
\text { effectiveness and } \\
\text { side effects. }\end{array}$ & $\begin{array}{l}\text { Continue to identify } \\
\text { possible obstacles } \\
\text { possibilities at home }\end{array}$ \\
\hline $\begin{array}{l}\text { Learning } \\
\text { session } 2 \\
\text { May }\end{array}$ & $\begin{array}{l}\text { Problems and improvement areas } \\
\text { What changes are we planning to make? } \\
\text { Clarifying goals } 1 \text { and } 2 \text { for the work. } \\
\text { Challenging consultations in } \\
\text { contraceptive counselling. }\end{array}$ & $\begin{array}{l}\text { Lectures and Discussions } \\
\text { Make an action plan on what improvement } \\
\text { actions will be tested in each department at } \\
\text { home. } \\
\text { A session in challenging consultations in } \\
\text { contraceptive counselling; How to avoid } \\
\text { conflicts and arguing for changes, how to } \\
\text { develop a shared agenda. }\end{array}$ & $\begin{array}{l}\text { Work with action plan, } \\
\text { prioritise and test } \\
\text { Record women's choice } \\
\text { of contraceptives } \\
\text { at the time of abortion. } \\
\text { Talk about the work with } \\
\text { colleagues at home }\end{array}$ \\
\hline $\begin{array}{l}\text { Learning } \\
\text { session } \mathbf{3} \\
\text { September }\end{array}$ & $\begin{array}{l}\text { Baseline measurement } \\
\text { Choice and start of contraceptive } \\
\text { method. } \\
\text { Analyse results so far } \\
\text { Women's views on teams' actions; } \\
\text { improve information and the } \\
\text { conversation about contraceptives. } \\
\text { How to provide respectful counselling } \\
\text { and support women in a behavioural } \\
\text { change }\end{array}$ & $\begin{array}{l}\text { Lectures and Discussions } \\
\text { Teams experiences working with the drivers } \\
\text { in each department and find new ideas } \\
\text { Reflect upon women's views in the QIC and } \\
\text { plan new actions. } \\
\text { A session in respectful counselling; } \\
\text { how to develop reflective listening, empathic } \\
\text { statements, shared decision-making } \\
\text { regarding contraception. }\end{array}$ & $\begin{array}{l}\text { Continue to record } \\
\text { women's choice of } \\
\text { contraceptives at the } \\
\text { time of an abortion } \\
\text { Talk about the work with } \\
\text { colleagues at home }\end{array}$ \\
\hline $\begin{array}{l}\text { Learning } \\
\text { session } 4 \\
\text { November }\end{array}$ & $\begin{array}{l}\text { Baseline measurements } \\
\text { Analyse results } \\
\text { Women's views on teams' actions } \\
\text { to improve access to LARC. } \\
\text { How to keep on pursuing the goal? } \\
\text { How can we create sustainability? }\end{array}$ & $\begin{array}{l}\text { Lectures and discussions } \\
\text { Reflect upon women's views in the QIC. } \\
\text { Group session for HPs, } \\
\text { who provide contraceptive counselling, } \\
\text { regarding experiences of improving } \\
\text { counselling. } \\
\text { Group session for secretaries } \\
\text { and invited statisticians about how to } \\
\text { collect data on goals fulfilment digitally. } \\
\text { Group discussion with teams, researchers and } \\
\text { invited heads of the three teams/ } \\
\text { departments. }\end{array}$ & \\
\hline
\end{tabular}




\section{Appendix 2. Visual aid ranking the effectiveness between different contraceptive methods (in Swedish)}

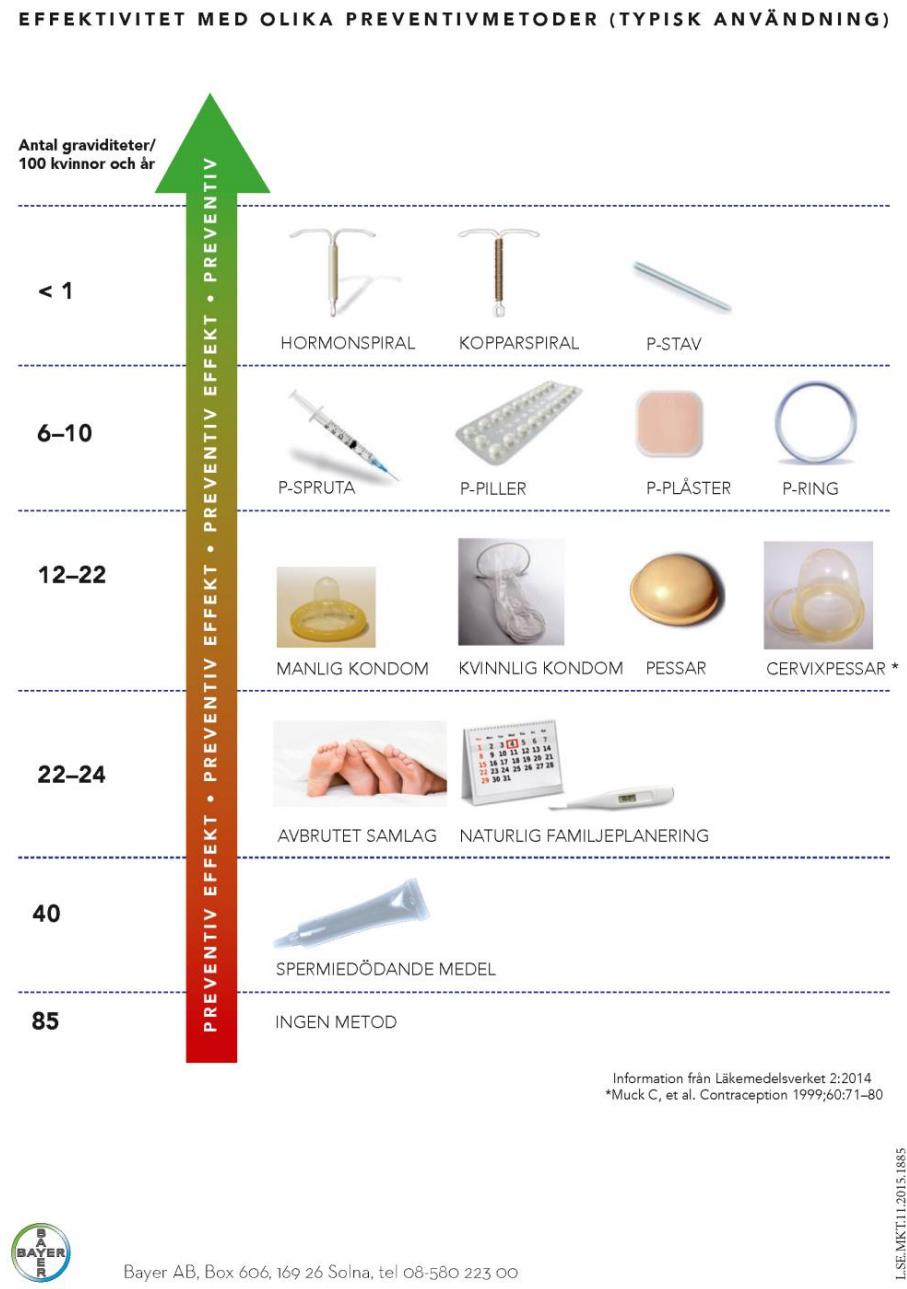

Used in the QIC and reprinted with permission of Bayer AB. 
Appendix 3. A decision aid regarding side effects of contraceptive methods (in Swedish).

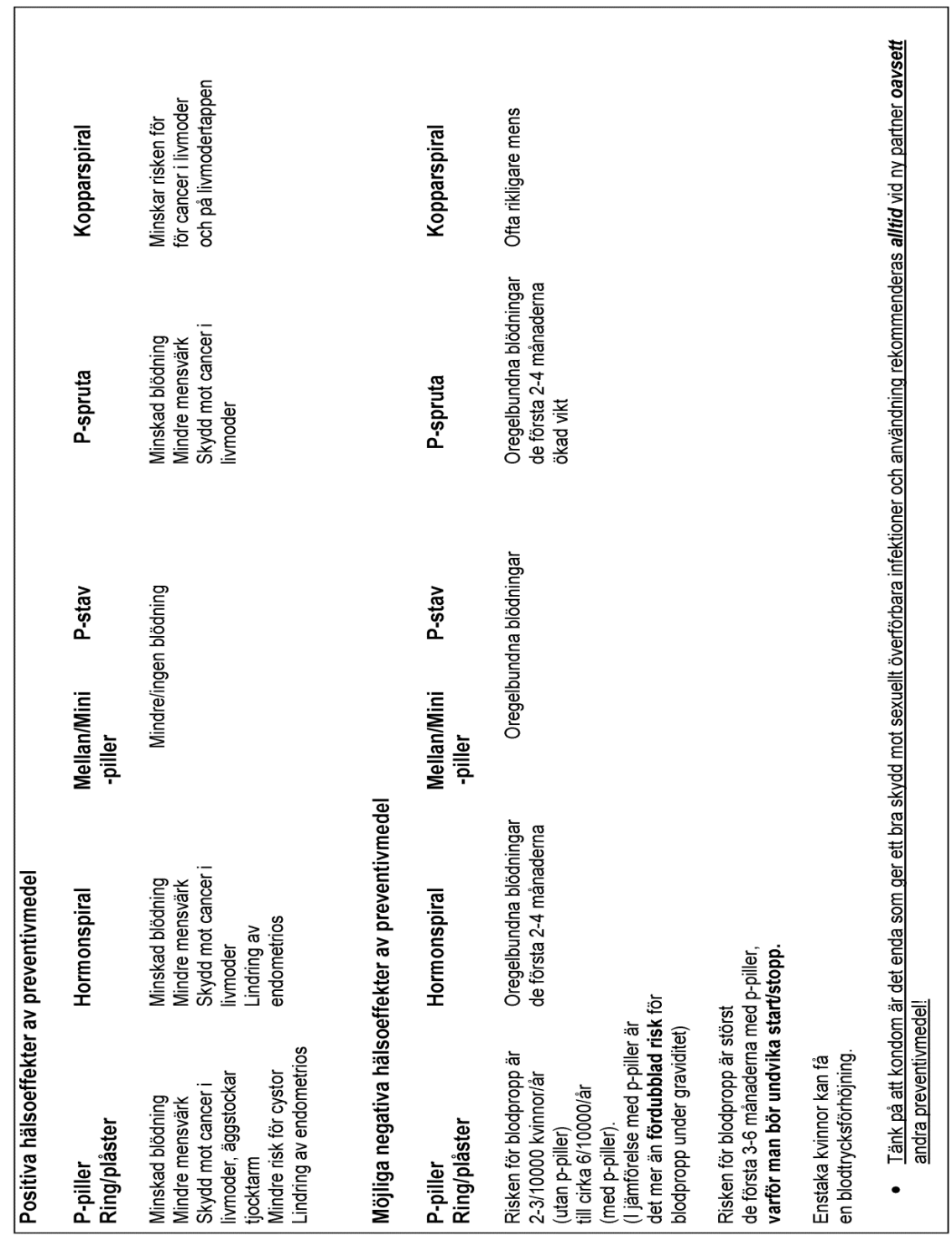


Appendix 4. Changes and spin-off changes in clinical practice during the QIC.

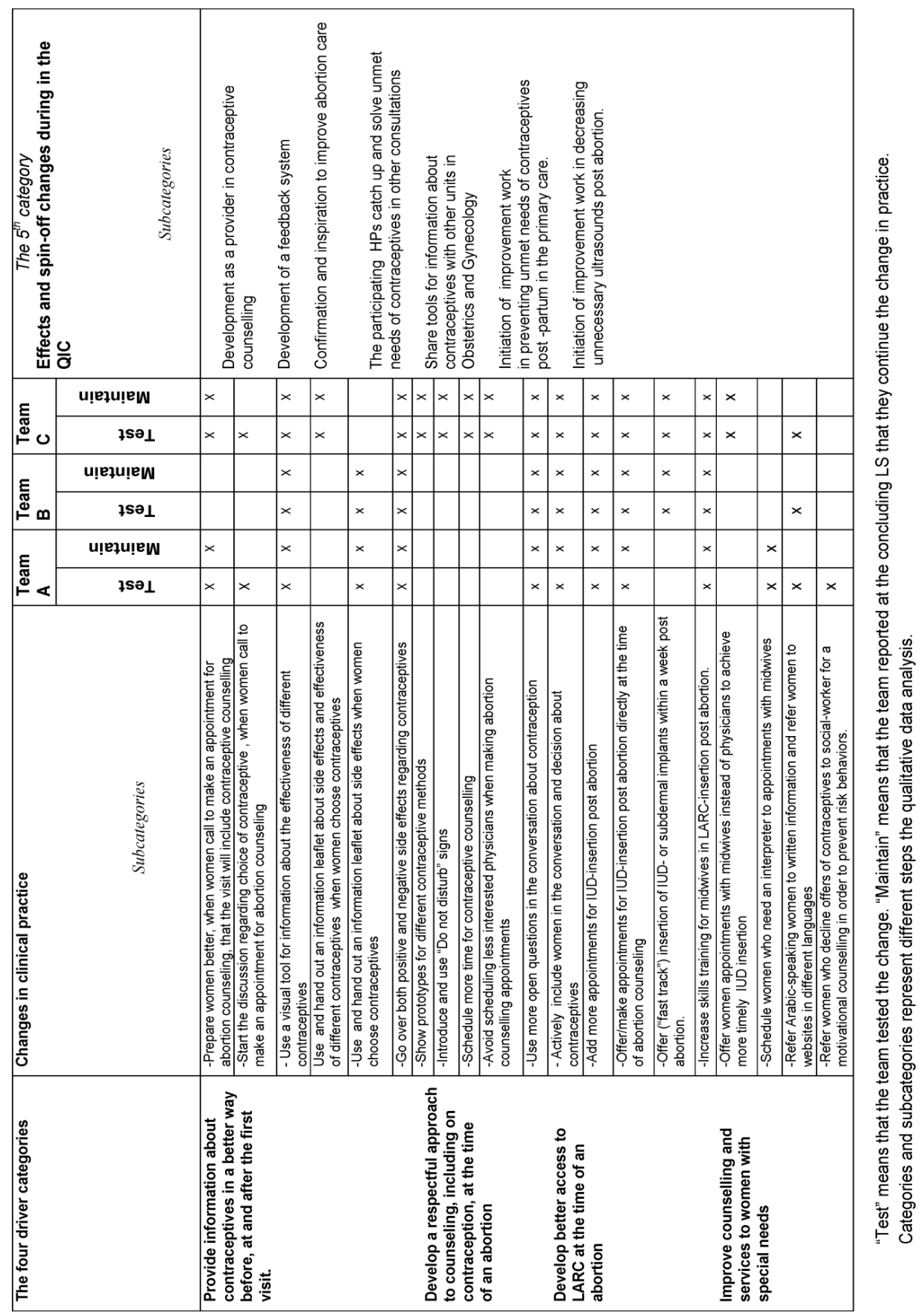




\section{Papers}

The papers associated with this thesis have been removed for copyright reasons. For more details about these see:

http://urn.kb.se/resolve?urn=urn:nbn:se:liu:diva-152875 